\title{
Finanzas públicas y administración en la provincia de Corrientes (1850-1889)
}

\author{
Enrique César Schaller \\ Instituto de Investigaciones Geohistóricas (CONICET), Facultad De Humanidades-Facultad de \\ Ciencias Económicas (UNNE), Argentina. \\ schaller53@gmail.com
}

Artículo recibido: 14 de febrero de 2018. Aprobación final: 13 de agosto de 2018.

\section{Resumen}

Con la vigencia de la Constitución de 1853, la Confederación Argentina, asociación de provincias unidas por pactos, fue sustituida por una república federal, alianza permanente en la que se creaban nuevas instancias de gobierno con atribuciones y recursos propios. Esta reforma implicó para las provincias una redefinición de sus funciones y estructuras estatales. En el ámbito de la hacienda pública el cambio fue profundo porque se modificaron las bases sobre las que se sustentaba el sistema rentístico provincial. En el presente artículo se analizan las reformas fiscales que tuvieron lugar en la provincia de Corrientes a partir de la organización nacional hasta las vísperas de la crisis económica de 1890. El período se caracteriza por la lenta construcción del nuevo régimen fiscal en un inestable contexto institucional. El estudio examina la evolución de los ingresos y gastos de la provincia y destaca los cambios más importantes que se produjeron en las diversas áreas del Estado.

Palabras clave: Organización Nacional, Finanzas públicas, Corrientes, Estado provincial.

Public Finances and Administration in Corrientes Province, Argentina (1850-1889)

\begin{abstract}
The National Constitution of 1853 established a federal republic, in which new instances of government were created with attributions and own resources, replacing the confederation of provinces united by pacts. This reform implied for the
\end{abstract}


provinces a redefinition of their functions and state structures. In the field of public finance, the change was profound because the bases on which the provincial rent system was based were modified. In this article we analyze the fiscal reforms that took place in the province of Corrientes from the national organization until the eve of the economic crisis of 1890. The period is characterized by the slow construction of the new fiscal regime in an unstable institutional context. The study examines the evolution of the income and expenditure of the province and indicates the most important administrative changes that occurred in the various areas of the State.

Keywords: National Organization, Public Finances, Corrientes, Provincial State.

\section{Introducción}

Con la vigencia de la constitución de 1853 la Confederación Argentina, débil alianza de unidades políticas soberanas, pasó a constituir una república federal. En esta asociación permanente las provincias acordaron ceder una parte de sus potestades y recursos para crear una autoridad nacional, instancia superior de gobierno destinada a superar las disputas regionales y a promover el crecimiento económico general. Asimismo, se comprometieron a instaurar en sus jurisdicciones el régimen municipal para promover la participación de la ciudadana en el manejo de los problemas locales. La puesta en práctica de este diseño institucional se caracterizó por el creciente predominio del Estado Nacional, el cual logró afianzarse como un poder hegemónico tanto en lo político como en lo económico. Las provincias, por su parte, aunque en grado diverso, también experimentaron una expansión de sus respectivas estructuras estatales. Este desarrollo fue en gran medida el resultado de la creciente capacidad de los diversos niveles de gobierno para financiar sus actividades con ingresos regulares. Debido a la importancia de la hacienda pública en la construcción estatal su análisis histórico ha dado lugar a una nutrida literatura académica que en el caso argentino se centró en la evolución de las finanzas de la Nación y la organización de su sistema monetario y bancario. ${ }^{1}$ En etapas más recientes se ha prestado mayor atención al papel de las provincias en la conformación del nuevo orden político-institucional razón por cual se han efectuado diversos trabajos sobre sus finanzas durante el siglo XIX aunque todavía persisten vacíos de información sobre algunas jurisdicciones y períodos. ${ }^{2}$ Como aporte al conocimiento de la construcción estatal en las provincias en este trabajo se examina la evolución de las finanzas públicas de Corrientes en el lapso comprendido entre 1850 y 1889. Durante este período se produjo la organización de un nuevo sistema fiscal en el cual las provincias tenían una amplia autonomía financiera. En el caso particular de la provincia de Corrientes, el lapso se destaca por la importancia de la adjudicación de tierras

1 El papel de las finanzas públicas en la construcción del Estado Nacional se analiza en Cortés Conde (1989); Garavaglia (2015); Gerchunoff, Rocchi y Rossi (2008); Oszlak (2015).

2 Sobre la evolución particular de las finanzas públicas de algunas provincias durante la etapa constitucional: Balán y López (1977); Bonaudo y Sonzogni (1997); Coria y Varo (2000); De los Ríos (2013); Herrera (2010); Herrera y Parolo (2012); Justiniano (2011); Rex Bliss (2004); Parolo y Fandos (2010); Schmit (2008). 
públicas como fuente regular de ingreso e instrumento de crédito. En este artículo se sintetiza la organización de las instituciones de la hacienda pública de la provincia, se presenta un panorama general de la evolución de sus ingresos y gastos, se examina el origen y composición de los recursos estatales, la distribución del gasto y el papel del crédito como fuente de financiamiento. Debe señalarse que aunque son numerosas las obras que tratan sobre la vida política correntina poco se ha escrito sobre la organización y funcionamiento del Estado provincial. ${ }^{3}$ La reconstrucción de sus finanzas provee algunos indicadores objetivos sobre estas cuestiones tales como las bases económicas sobre las que se sustentó la acción estatal, la organización de las reparticiones del Estado, la relación entre los diversos niveles de gobierno y la orientación de las políticas públicas, por citar algunos aspectos.

\section{Fuentes y unidades monetarias}

Los datos estadísticos de recursos y erogaciones de la provincia incluidos en este trabajo son de elaboración propia en base a diversas fuentes. Para el lapso de 1850 a 1862 se utilizaron los Libros de Caja y Contaduría guardados en el Archivo Histórico de la provincia. La serie se interrumpe como resultado de las reformas de las reparticiones de hacienda y hasta el presente no se ha logrado ubicar los libros contables de la nueva etapa. No obstante, en la colección "Expedientes Administrativos" del Archivo se han encontrado copias de los registros de 1863 a 1868,1870 y de 1885 a 1888. Para los años restantes se utilizaron publicaciones oficiales. Entre las editadas por el gobierno de la provincia de Corrientes se destacan los mensajes de los gobernadores, que suelen incluir valiosos anexos, la "Memoria del Ministerio de Hacienda" del año 1879 y los Registros oficiales. De las publicaciones nacionales son fundamentales los informes anuales del presidente del Crédito Público, Pedro Agote. Finalmente también se consultaron periódicos locales del período $1855-1864 .^{4}$

\footnotetext{
3 Sobre la organización del estado correntino durante el siglo XIX la obra más completa es aún la de Gómez (1922). Para la primera mitad del siglo XIX se cuenta con el trabajo fundamental de Chiaramonte (1991); para los inicios período constitucional son valiosas las reflexiones de Buchbinder (2004).

4 Fuentes: Período 1850-1862, Archivo Histórico de la Provincia de Corrientes (AHPC, en adelante), Libros de Caja, tomos 91 a 110; Periódicos El Comercio (1854-1858), La Opinión (1859), La Unión Argentina (1860-1861), La libertad (1862), El Progreso (1863-1865). Período 1863-1870: AHPC, Expedientes Administrativos, legajos 137 a 149; Mensaje del gobierno de la provincia a la Legislatura al abrirse el período de sus sesiones ordinarias de 1863, Corrientes, El Progreso; "Mensaje del P. Ejecutivo a la H.C. Legislativa de la provincia al abrir sus sesiones ordinarias", Registro Oficial de la Provincia de Corrientes, año 1869, segundo semestre, Corrientes, La Esperanza; Echeverría y Contreras (1873). Período 18711874: AHPC, Mensaje del Poder ejecutivo a la Honorable C.L. de la Provincia, Corrientes, El Argos, 1874; Mensaje del gobernador de la provincia al abrir las sesiones de la H.C. Legislativa en julio de 1875, Corrientes, El Argos. Período 1875-1883: Agote (1885, 1887 y 1888); AHPC, Memoria del Ministerio de Hacienda de la provincia de Corrientes. 1879. Corrientes, La Libertad; Mensaje del Poder Ejecutivo de la provincia al abrir las sesiones de la H. Cámara Legislativa en julio de 1882, Corrientes, El Autonomista; Mensaje del Poder Ejecutivo a la Honorable Cámara Legislativa de la Provincia de Corrientes al abrir sus sesiones ordinarias en julio de 1883, Corrientes, La Verdad; Período 1884-1889: AHPC, Expedientes Administrativos, legajos 208 a 215; Mensaje del Poder Ejecutivo a la Honorable Cámara Legislativa de la provincia de Corrientes al abrir sus sesiones ordinarias en julio de 1884, Corrientes, El Autonomista; Mensaje del gobernador de la provincia al inaugurar las sesiones ordinarias de la Legislatura en el presente período, mayo de 1891, Corrientes, Fages.
} 
En cuanto a las unidades monetarias hay que señalar que entre 1841 y 1863 las cuentas de la provincia están expresadas en moneda metálica y en moneda corriente. La primera era el peso plata de ocho reales del período colonial que en relación con el oro se cotizaba a diecisiete pesos la onza (25 gramos). La segunda correspondía a los billetes inconvertibles emitidos por el gobierno provincial y cuya cotización con la moneda metálica era muy variable. Para unificar los valores se han utilizado las equivalencias que aparecen en los periódicos locales. Entre 1864 y 1882 la unidad utilizada fue el peso fuerte de plata que de acuerdo con la ley nacional del 22 de octubre de 1863 se cotizaba a dieciséis pesos la onza. A partir de 1883 se empleó el peso moneda nacional y los billetes del Banco Nacional comenzaron a reemplazar a la moneda metálica. El peso papel era convertible con su equivalente metálico (el peso oro de 1,6 gramos de valor similar al peso fuerte). Sin embargo, en 1885 se abandonó la convertibilidad y el billete perdió valor en relación con el metálico aunque en este trabajo se han mantenido sin cambios los montos que aparecen en la documentación ${ }^{5}$

\section{Antecedentes. Las finanzas correntinas en la etapa previa a la organización nacional}

Hasta la organización constitucional del país las provincias eran unidades administrativas y fiscales independientes. Como tales, salvo situaciones excepcionales, sus ingresos provenían de los recursos que recaudaban en su propia jurisdicción. De todas las entradas regulares las más importantes eran los impuestos que se aplicaban al comercio con otros distritos. Para percibirlos cada provincia instaló aduanas en los puntos estratégicos de su jurisdicción. La provincia de Corrientes, formada a partir de 1814, estableció aduanas en los puertos sobre el río Paraná (Corrientes, Bella Vista, Goya y Esquina) y sobre el Uruguay (Paso de los Libres y Santo Tomé). Además de los derechos aduaneros el Estado correntino obtenía ingresos regulares de otros impuestos (Patentes, Diezmo, Sellados, Derechos Policiales) y, descle 1831, del canon enfitéutico. Esta organización rentística alcanzó su madurez durante la década de 1830. Entre 1835 y 1837, los años de mejor recaudación, la media de los ingresos llegó a \$134.000. Una de las características salientes de las finanzas del período fue el equilibrio fiscal ya que, salvo circunstancias excepcionales, las erogaciones se ajustaban estrictamente a la recaudación (Chiaramonte, 1991: Cap. I).

A partir de 1838 la provincia inició una larga lucha contra el dictador porteño Juan Manuel de Rosas. Este conflicto, que se prolongó hasta 1847, fue muy destructivo y contribuyó a empobrecer la economía local. En ese lapso las finanzas fueron permanentemente deficitarias por la caída de las rentas y el aumento del gasto militar. Además, junto con las erogaciones registradas por la tesorería se

5 La cotización del peso oro en pesos papel fue la siguiente: $1885: 1,37 ; 1886: 1,39 ; 1887: 1,35 ; 1888$ : 1,48; y 1889: 1,80. Ver Álvarez (1929). Debe señalarse, sin embargo, que al parecer esta depreciación tardó en trasladarse a los precios locales. Recién en 1890 el gobernador en su mensaje anual hace referencia a una caída de las rentas como resultado de la desvalorización de la moneda. 
fue acumulando una enorme deuda flotante de monto desconocido, que resultó de las requisiciones, empréstitos forzosos y daños resultantes de la lucha. Recién en los últimos años de la década de 1840 la situación fiscal tendió a regularizarse con el retorno paulatino de la paz.

Cuadro 1. Ingresos y gastos de la provincia de Corrientes (1838-1849).

\begin{tabular}{cccc}
\hline Año & Ingresos & Gastos & Saldo \\
\hline 1838 & 112.692 & 116.293 & -3.601 \\
1839 & 107.092 & 120.682 & -13.590 \\
1840 & 103.107 & 100.442 & -3.263 \\
1841 & 101.442 & 177.787 & -76.345 \\
1842 & 94.620 & 251.002 & -159.834 \\
1843 & 74.610 & 214.444 & -139.834 \\
1844 & 95.258 & 187.327 & -92.069 \\
1845 & 118.608 & 127.589 & -8.981 \\
1846 & 203.191 & 193.988 & 9.203 \\
1847 & 164.538 & 147.609 & 16.929 \\
1848 & 95.543 & 93.118 & 2.425 \\
1849 & 108.414 & 95.147 & 13.267 \\
\hline
\end{tabular}

Fuente: Archivo Histórico de la Provincia de Corrientes. Libros de Caja.

El incremento extraordinario del gasto registrado que se observa a partir de 1841 se debió a que el gobierno encontró una fuente regular de financiamiento con la emisión del papel moneda inconvertible. La primera serie de \$100.00 comenzó a circular por la ley del 23 de julio de 1841. A diferencia de lo que ocurrió en otras jurisdicciones el billete local fue aceptado por la población y se difundió en todo el territorio provincial. A esta primera emisión le siguieron otras por lo que a fines de 1847 la circulación llegaba a \$632.869. A partir de 1848 no se realizaron nuevas emisiones pero el aumento de la cantidad de billetes había producido una fuerte desvalorización de los mismos. Hacia 1850 la relación entre el peso papel y el metálico era de seis a uno. Se hicieron algunos intentos para retirar los billetes pero la provincia no contaba con los fondos para cambiarlos por metálico. De esta forma, al iniciarse la etapa constitucional el papel moneda local estaba en circulación y P.E. conservaba la potestad emitirlo en forma discrecional (Schaller, 2000).

\section{Las reformas de la etapa constitucional}

La organización de la república federal iniciada tras la caída de Rosas planteó la necesidad de definir las atribuciones fiscales de los diversos niveles de gobiernos establecidos por el nuevo ordenamiento institucional. Sin duda, la cuestión fundamental era la separación de las rentas de las provincias y de la Nación. En este aspecto, los principios básicos quedaron definidos en el acuerdo de San Nicolás (31 de mayo de 1852). En él las provincias acordaron otorgar a la autoridad nacional la facultad exclusiva para regular el comercio exterior de la república y de recaudar derechos de importación y exportación. La potestad tributaria se complementaba con la disposición que establecía la libre circulación de bienes dentro del territorio 
argentino. Posteriormente la Constitución Nacional de 1853 consagró definitivamente estos preceptos. De esta forma debían pasar a la jurisclicción nacional las aduanas habilitadas al intercambio con otros países y tenían que suprimirse las que gravaban el comercio interprovincial (Chiaramonte, 1993; Botana, 1993).

Las disposiciones constituían requisitos básicos para consolidar la unidad nacional ya que creaban un poder central con abundantes recursos y facilitaban la integración económica. Asimismo, la constitución institucionalizó mecanismos por los cuales todas las provincias podían beneficiarse, por medio de subsidios y obras públicas, de las rentas provenientes del comercio de ultramar. En el corto plazo, sin embargo, para los estados provinciales la pérdida de sus aduanas significaba resignar su principal fuente de ingresos sin una compensación. En adelante sus recursos dependerían de la recaudación de impuestos a los capitales y a las transacciones internas por lo que debían realizar una reforma de fondo de la organización fiscal.

Hasta 1852 el único punto habilitado al comercio exterior era el puerto de Buenos Aires pero durante ese año (decretos del 28 de agosto y del 31 de octubre) la autoridad nacional provisoria ejercida por Justo José De Urquiza estableció que los principales puertos fluviales del Litoral, entre ellos los de la provincia de Corrientes, quedaban abiertos al intercambio con el extranjero. Estas aduanas por su condición de exteriores debían transferirse a la jurisdicción nacional. Sin embargo, el traspaso definitivo se demoró debido a las dificultades de las nuevas autoridades nacionales para organizar su sistema rentístico. En el caso de Corrientes durante tres años las aduanas continuaron administradas por la provincia y en ellas se percibieron impuestos aduaneros provinciales y los nuevos aranceles que estableció la Nación. ${ }^{6}$ El período de transición concluyó finalmente con la creación de la Administración de Rentas Nacionales la cual, a mediados de 1855 se hizo cargo de las aduanas. Este traspaso no fue definitivo porque la provincia recuperó la administración aduanera durante cerca de un año (del 17 de diciembre de 1861 al 25 de octubre de 1862) en el interregno comprendido entre la disolución de las autoridades nacionales tras la batalla de Pavón y la elección de Bartolomé Mitre como presidente constitucional. ${ }^{7}$

La instauración del régimen municipal también implicó una transferencia de recursos provinciales aunque en una escala mucho menor. En la provincia de Corrientes los primeros municipios autónomos comenzaron a funcionar a principios de 1864 pero por dificultades económicas y políticas el régimen tardó en afianzarse. Hacia 1888 además de la ciudad de Corrientes sólo ocho de las

6 El decreto del 31 de octubre de 1852 determinaba que, mientras se arreglara la tarifa definitiva las aduanas percibirían los derechos provinciales más un adicional del 7\% destinado al gobierno nacional. Recién en diciembre de 1853 al entrar en vigencia el "Estatuto para la Organización de la Hacienda y el Crédito Público" quedaron definidos los derechos aduaneros de la Nación. Al aplicarse esta tarifa automáticamente perdían vigencia los derechos provinciales. Pese a ello, la legislatura correntina el 18 de enero de 1854 aprobó una ley que estableció impuestos aduaneros que estuvieron vigentes hasta el traspaso definitivo. Pujol (1911: 20).

7 El gobierno correntino designó un Administrador General de Rentas que refundía el cargo de Administrador de Aduana nacional y el de Colector General de la provincia. De todas formas, las cuentas de las aduanas se registraban en forma separada de las que correspondían a las rentas provinciales. Registro Oficial de la Provincia de Corrientes (R. O., en adelante), Año 1862, pp. 13- 14 y 187-188. 
veinticinco poblaciones cabecera de departamento en el interior contaban con un gobierno municipal. La provincia transfirió a las comunas el manejo de los denominados Derechos Policiales (más tarde denominados municipales) y, hasta 1879, parte de la recaudación de la Contribución Directa. Desde 1869 las poblaciones que no contaban con municipios fueron administradas por Comisiones Departamentales designadas por el P.E. Éstas disponían de los Derechos Policiales pero bajo la supervisión directa del gobierno provincial.

\section{La reorganización de la Hacienda provincial}

Antes de la nacionalización de las aduanas la estructura de la hacienda correntina respondía a un esquema simple en consonancia con los limitados recursos económicos y humanos disponibles. La creación de un nuevo sistema fiscal basado en la percepción de impuestos a la riqueza particular y el crecimiento de la actividad económica requería una organización mucho más compleja. En Corrientes, como en la mayoría de las provincias inicialmente la carencia de personal y de información demoró las transformaciones lo que a su vez repercutió negativamente en la recaudación.

En base al principio de la división de poderes el gobernador era el responsable de la administración de la hacienda pública en tanto que la legislatura local tenía la potestad de votar los impuestos y de supervisar el manejo de los fondos. A partir de la constitución provincial de 1856 la administración de los recursos debía estar regida por un presupuesto que se aprobaba anualmente. Desde 1870 se estableció además la práctica de votar anualmente una ley general de impuestos. También se sistematizaron los procedimientos para el manejo de los fondos públicos aunque una ley de contabilidad recién se aprobó el 27 de diciembre de $1888 .^{8}$

Desde 1825 la repartición superior especializada en el manejo de las finanzas era la Colecturía General que reunía una amplia variedad de funciones. En 1860 se crearon los ministerios de Gobierno y de Hacienda con lo cual se diferenció la tarea político-administrativa vinculada con las decisiones sobre impuestos y asignación de gastos de la labor puramente técnica de la Colecturía. En 1861 se estableció la Mesa Topográfica destinada inicialmente al examen las mensuras y la tasación de los terrenos. ${ }^{9}$ En 1873 la Colecturía se dividió en la Contaduría General, encargada de liquidar las cuentas y controlar los pagos y la Tesorería General, responsable de registrar los movimientos de caja y de la recaudación en la capital. ${ }^{10}$ En el nivel inferior de la administración se encontraban las receptorías de rentas que funcionaban en los departamentos del interior de la provincia. La

8 R.O., Año 1888, Corrientes, 1913, pp. 386-408.

9 Debido a la escasez de recursos ambas reformas fueron anuladas en 1862. Sin embargo, el cargo de Ministro Hacienda fue restablecido en 1866 y el alcance de sus atribuciones fue determinado por decreto del 23 de marzo de 1869. La Mesa Topográfica volvió a crearse en 1867. Esta repartición además de la tramitación de las denuncias de tierras fiscales pasó a ser la entidad técnica encargada de asesorar al gobierno sobre las obras públicas. "Mensaje del P. Ejecutivo a la H.C. Legislativa de la provincia al abrir sus sesiones ordinarias", R.O., año 1869, segundo semestre.

10 AHPC, Mensaje del Poder ejecutivo a la Honorable C.L. de la Provincia, Corrientes, El Argos, 1874 
reforma del sistema impositivo reforzó la importancia de estas oficinas dado que gran parte de los ingresos provenían de la percepción gravámenes sobre el valor de las propiedades rurales y el ganado. ${ }^{11}$ No obstante, debido a la escasez de recursos, salvo en la ciudad de Goya, durante varios años las receptorías quedaron a cargo de los jueces paz.Éstos como autoridades superiores del departamento además de sus funciones judiciales desempeñaban tareas administrativas y fiscales. Recién a partir de la ley del 24 de septiembre de 1870 las funciones de hacienda se separaron con la designación receptores con sueldo. ${ }^{12}$

Pese a las reformas existían grandes limitaciones en cuanto a información y recursos humanos. Ello se manifestaba en el hecho de que la recaudación de la Contribución Directa y las Patentes, impuestos de mayor importancia para los ingresos fiscales, no estuviera totalmente a cargo de funcionarios sino que se delegaba a comisiones ad hoc. En lo que se refiere a la Contribución Directa que gravaba los inmuebles y el ganado, el principal obstáculo era la falta de datos sobre el patrimonio de los contribuyentes. Para limitar los fraudes, la confección de los padrones anuales de contribuyentes en la ciudad capital y en cada departamento estaba a cargo de comisiones integradas por tres "capitalistas" designados por el gobierno quienes recibían un porcentaje de los recaudado ( $4 \%$ o 5\% de acuerdo con los años). La labor inicial de las comisiones fue muy deficiente puesto que el incentivo económico no solucionaba la dificultad de gravar los patrimonios sin una base cierta. Las falencias sólo se fueron superando en forma paulatina con una mayor intervención de los funcionarios y un perfeccionamiento de los registros. ${ }^{13}$ Las Patentes, por su parte, gravaban las actividades lucrativas y el monto del impuesto dependía del tipo de negocio de acuerdo con una clasificación establecida por la ley. Hasta mediados de la década de 1870 la asignación de las patentes correspondió a los funcionarios estatales. Luego se transfirió a comisiones de dos integrantes designados por el P.E. porque la labor era mucho más compleja debido a la multiplicación de negocios y oficios.

\section{Evolución de los ingresos y gastos de la provincia de Corrientes (ver cuadro I del anexo)}

La transferencia de las aduanas fluviales en 1855 inició una nueva etapa para las finanzas públicas de la provincia. Desde ese año hasta 1869 se produjo la construcción de un nuevo sistema impositivo en un contexto político institucional

11 En la etapa en que existían los derechos aduaneros, la ciudad de Corrientes, como principal puerto de la provincia concentraba entre el $70 \%$ y el $80 \%$ de la recaudación. Para fines de la década de 1870 esta participación había caído a alrededor del 48\%. Cfr. AHPC, Memoria del Ministerio de Hacienda, 1879.

12 R.O., Año 1870, 2o semestre.

13 A partir de 1860 las comisiones fueron presididas por el Colector, más tarde Tesorero, en la capital y en los departamentos, inicialmente por el jefe político o el juez de paz y luego por el receptor de rentas. Desde 1864 en las localidades con municipios la organización de las comisiones quedó a cargo de los Ayuntamientos que por esta labor percibían el $10 \%$ de lo recaudado. La participación de los municipios se mantuvo hasta 1879 y a juzgar por las declaraciones de los gobernadores los resultados no fueron satisfactorios. Una herramienta fundamental para establecer el impuesto era el registro de las propiedades urbanas y rurales. En 1859 el gobernador Juan Pujol encargó la confección de un mapa catastral de la provincia pero el trabajo resultó muy deficiente por lo que hasta fines de la década de 1880 se careció de este instrumento. El primer mapa catastral de la provincia es de 1894. 
muy inestable. A partir de 1870 los cambios introducidos se reflejaron en una sostenida mejora en la recaudación aunque siempre dentro de un marco estrecho que sólo permitía avances paulatinos en la organización y funciones del Estado

En cuanto a la administración de los fondos públicos hasta principios de la década de 1880 el objetivo prioritario fue la búsqueda del equilibrio fiscal. La función del gobierno era crear las condiciones estabilidad y seguridad jurídica para el crecimiento económico sin gravar excesivamente la riqueza particular. Esta prudencia respondía también a las dificultades para recaudar de los impuestos y para financiar el déficit por medio del endeudamiento. Sin embargo, la disciplina fiscal era imposible en los frecuentes períodos de inestabilidad de la época. En ellos el aumento del gasto extraordinario normalmente coincidía con una caída de las rentas lo que resultaba en un fuerte incremento de la deuda flotante.

Gráfico 1. Evolución de los ingresos y gastos de la provincia (pesos)

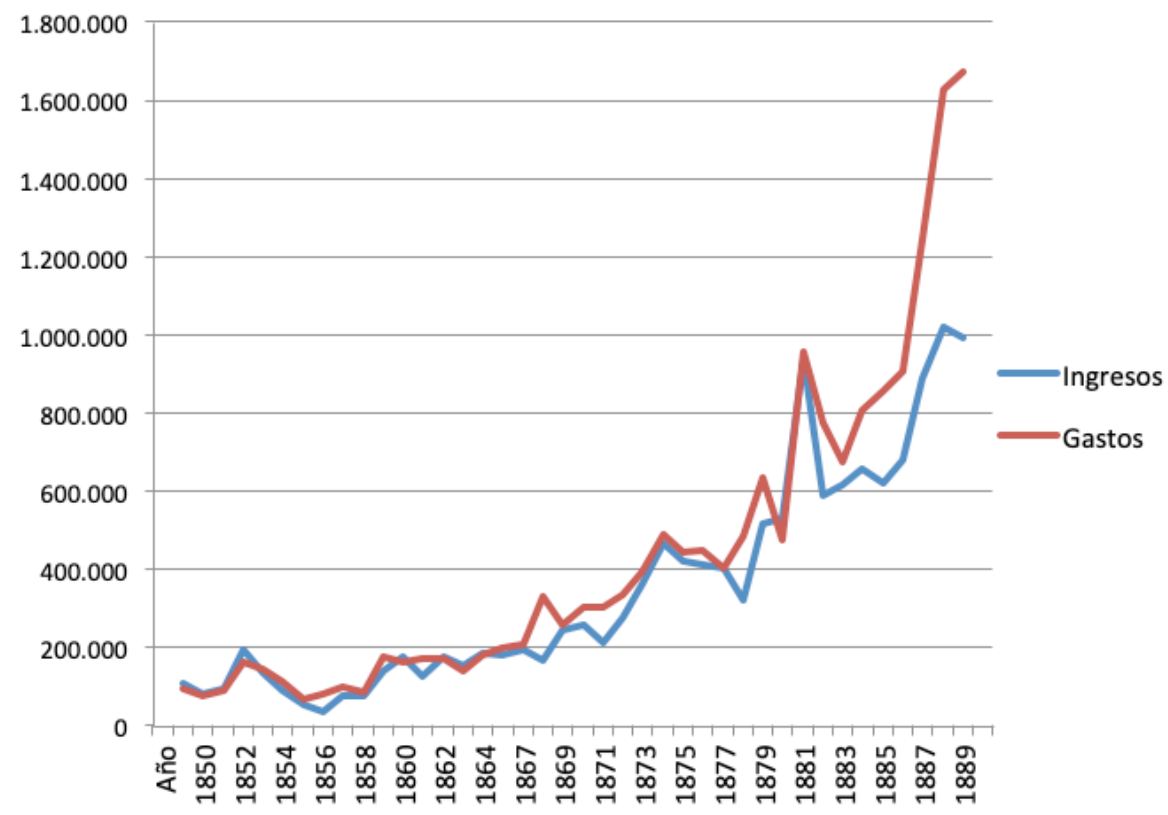

Cuadro 2. Ingresos y gastos de la provincia de Corrientes (1850-1889). Monto anual promedio por quinquenio en pesos.

\begin{tabular}{crccc}
\hline Período & Ingresos & Gastos & $\begin{array}{c}\text { Superávit } \\
\%\end{array}$ & $\begin{array}{c}\text { Déficit } \\
\%\end{array}$ \\
\hline $1850-1854$ & 120.900 & 117.800 & 2,6 & \\
$1855-1859$ & 77.600 & 101.900 & & 31,3 \\
$1860-1864$ & 164.800 & 160.300 & 2,7 & \\
$1865-1869$ & 198.000 & 248.500 & & 25 \\
$1870-1874$ & 317.000 & $\dot{2} 365.500 ?$ & & $115,3 ?$ \\
$1875-1879$ & 417.400 & 483.300 & & 15,8 \\
$1880-1884$ & 599.200 & 684.500 & & 49,2 \\
$1885-1889$ & 841.600 & 1.260 .000 & & 49,7 \\
\hline
\end{tabular}

En los últimos años del período rosista (1848-1851) la recaudación de la provincia se había estabilizado en niveles inferiores a los alcanzados en la década de 1830. A 
partir de 1852 se inició el proceso de cesión de las aduanas que, como se ha visto, recién se completó en 1855 . En ese lapso, aunque continuaron cobrándose derechos aduaneros provinciales el gobierno los redujo considerablemente como muestra de adhesión a la política nacional. En consecuencia, desde 1853 los ingresos anuales comenzaron a disminuir y esta caída se acentuó al concretarse la transferencia definitiva. El momento más crítico ocurrió entre los años 1855 y 1858 en los que la media anual de los ingresos fue cerca de la mitad del promedio del quinquenio 1850-1854. Esta caída de las rentas, sin embargo, no dio lugar a una reducción similar de los gastos en gran medida porque la administración durante un tiempo pudo financiarse con nuevas emisiones de papel moneda local. ${ }^{14}$

A partir de 1859 los recursos volvieron a crecer gracias a la venta de tierras fiscales y la paulatina reconstrucción del sistema impositivo. En el quinquenio de 1860-1864 el ingreso anual promedio de la provincia fue 112\% superior al del lustro anterior. Tras esta fuerte recuperación la recaudación tendió a estancarse y así en el lapso de 1865-1869 la media de lo percibido sólo creció un 16\%. Hay que tener en cuenta que durante la década de 1860 la reorganización del sistema fiscal y, en general, la actividad del Estado estuvo fuertemente condicionada por las crisis políticas y bélicas que se sucedieron en esa etapa. ${ }^{15} \mathrm{~A}$ los años de recaudación regular $(1860,1863,1864,1867,1869)$ le sucedieron otros con una fuerte disminución de los ingresos corrientes (1861, 1862, 1865, 1866 y 1868). Aún así los desequilibrios no fueron muy grandes debido a que gobierno nacional en los momentos de crisis otorgó subsidios que en parte compensaron las caídas. Las únicas excepciones fueron 1861 y 1868 ya que los gastos que produjeron la movilización de las milicias debieron ser solventados por el tesoro provincial. En lo que respecta al uso del crédito, con la generalización de la venta de tierras fiscales y el rescate del papel moneda correntino por parte de la Nación, a partir de 1863 el estado provincial logró obtener recursos adicionales y afrontar la deuda de ejercicios anteriores mediante el otorgamiento de bonos que rendían un interés y podían utilizarse para la compra de tierras públicas.

Durante la década de 1870 los enfrentamientos facciosos y los levantamientos militares fueron frecuentes pero la labor administrativa fue más regular ${ }^{16}$ Este proceso de afirmación del Estado resultó en una mejora en la recaudación. Así las reformas fiscales de los años anteriores lograron resultados apreciables con un incremento de los ingresos corrientes más acorde con el crecimiento de la riqueza y la producción locales. En conjunto en el lapso 1870-1874, la recaudación anual media, fue 60\% superior a la del quinquenio anterior y en el período 1875-1879

14 De esta forma en algunos años la brecha entre ingresos y gastos alcanzó niveles extraordinarios para tiempos de paz (181\% en 1855 y $47 \%$ en 1856$)$.

15 Como resultado de la crisis del gobierno confederal tras la batalla de Pavón en Corrientes se produjo una rebelión liberal que destituyó al gobernador (diciembre de 1861) y mantuvo movilizada las milicias provinciales durante el año 1862. La invasión paraguaya en abril de 1865 que marcó el comienzo de la guerra de la Triple Alianza desorganizó por completo la actividad administrativa provincial. Finamente en 1868 se produjo una nueva rebelión liberal.

16 Las fuerzas militares de la provincia fueron movilizadas para repeler la invasión de las fuerzas entrerrianas de López Jordán (1871 y 1873), por la lucha entre las facciones del partido liberal (1872), para prevenir revueltas internas a raíz de la rebelión mitrista que siguió a la elección presidencial (1874) y por un conflicto los partidos liberal y autonomista (1878-1879) 
el crecimiento fue de cerca del 32\%. En lo que se refiere a los gastos, durante la mayor parte del decenio prevaleció la prudencia a la que también contribuyó no poco la crisis financiera que afectó al país a partir de 1873. No obstante, en 1870-1872 y 1878-1879, años de conflictos internos, el déficit fue considerable

A diferencia de etapas anteriores la década de 1880 constituyó un período en el que prevaleció la paz interna. La consolidación del orden repercutió más en los gastos que en los ingresos. La recaudación media del quinquenio de 1880-1884 fue un $43 \%$ superior a la del lustro previo. En la segunda mitad de la década el aumento en términos nominales fue de cerca del 29\% y esta proporción es aún menor si se tiene en cuenta la depreciación que experimentó la moneda nacional a partir de 1885. Por el contrario, los gastos en términos nominales y reales crecieron en forma regular a lo largo de casi todo el período por lo que los déficits anuales tendieron a ampliarse. Este incremento resultaba de la mayor facilidad de acceso al crédito a partir de la instalación de una sucursal del Banco Nacional en 1879. Los préstamos del banco constituyeron un mecanismo mucho más ágil que la adjudicación de bonos. Paulatinamente se fue dejando de lado la búsqueda del equilibrio fiscal en favor de una ampliación del gasto para impulsar las obras públicas y el crecimiento económico. La orientación finalmente se impuso durante la administración de Juan Ramón Vidal (1886-1889) con la creación de un Banco provincial y la contratación del primer empréstito externo dentro del marco establecido por la ley nacional de Bancos Garantidos. Esta política expansiva no se correspondía con las posibilidades reales del gobierno y en poco tiempo la crisis de 1890 produjo un retorno a la ortodoxia fiscal.

De todas formas pese a las crónicas limitaciones del financiamiento provincial era evidente que se habían logrado notables avances que pueden apreciarse en la evolución del monto per cápita de la recaudación y de los gastos fiscales. ${ }^{17}$

Cuadro 3. Ingresos y gastos fiscales por habitante en la provincia de Corrientes (pesos)

\begin{tabular}{llccrrrr}
\hline & & 1835 & 1850 & 1857 & 1869 & 1875 & 1885 \\
\hline \multirow{2}{*}{ Provincia } & Ingresos & 2 & 1,5 & 0,9 & 1,9 & 2,8 & 3,4 \\
& Gastos & 1,9 & 1,4 & 1,2 & 2 & 3 & 4,3 \\
\hline \multirow{2}{*}{$\begin{array}{l}\text { Nación + Provincia + } \\
\text { Municipios }\end{array}$} & Ingresos & - & - & 4 & 3,9 & 5 & 5,2 \\
\hline
\end{tabular}

La prolongada lucha contra Rosas durante la década de 1840 produjo una crisis en la economía provincial que se manifestó en el estancamiento demográfico y la fuerte caída de las rentas. ${ }^{18} \mathrm{En}$ la segunda mitad del siglo XIX,superada la crisis fiscal por la pérdida de las aduanas a partir de la década de 1860 el crecimiento de los ingresos y agastos superó ampliamente el incremento demográfico lo que

17 Fuentes del cuadro Población: Datos sobre 1835, 1850 y 1857 en Maeder (1969); 1875 y 1885 cálculo en base a la tasa de crecimiento medio anual entre 1869 y 1895 . Ingresos y gastos de la provincia en 1835, a partir de Chiaramonte (1991). Ingresos y gastos nacionales: 1857, datos de Garavaglia (2015: 63); 1869, 1875 y 1885, Memorias del Ministerio de Hacienda de la Nación. Finanzas municipales: presupuestos publicados en los Registros Oficiales.

18 Población de la provincia de Corrientes: 1833: 55.897 habitantes; 1841: 57.309; 1857: 85.477; 1869: 129.023; 1895: 239.788. Tasas de crecimiento medio anual: $1833-1841$ : 0,3\%; 1841-1857: 2,6\%; $1857-$ 1869: $3,4 \% ; 1869-1895: 2,3 \%$ 
indicaba la mayor eficacia de la organización rentística provincial y un aumento de la capacidad contributiva de la población. En este último aspecto hay que tener en cuenta que funcionaban tres niveles de gobierno por lo que en la provincia también se recaudaban rentas nacionales y municipales.

\section{Composición de los ingresos provinciales (Ver además cuadro II del anexo)}

Durante la etapa previa a la organización nacional los ingresos regulares de la provincia dependían de manera sobresaliente de los derechos aduaneros. A partir de la transferencia de las aduanas el origen de los recursos fue un poco más variado. La adjudicación de tierras públicas pasó a ser una fuente de ingresos similar a la percepción de impuestos. Creció el número de tributos aunque las entradas principales provenían de tres gravámenes (Contribución Directa, Patentes y Guías de Hacienda). Una novedad fundamental fue la obtención de subsidios otorgados por el gobierno nacional que en esta etapa representaron un aporte suplementario a los ingresos de la provincia. La importancia de estas fuentes dentro del conjunto de las rentas fue variando a lo largo del período estudiado.

Cuadro 4. Ingresos de la provincia de Corrientes. Promedio anual y participación en el total de las rentas.

\begin{tabular}{lcccccccr}
\hline & \multicolumn{2}{c}{ Impuestos } & \multicolumn{2}{c}{ Tierras } & \multicolumn{2}{c}{ Subsidios } & \multicolumn{2}{c}{ Eventuales } \\
\hline Período & Monto & $\%$ & Monto & $\%$ & Monto & $\%$ & Monto & $\%$ \\
\hline $1850 / 1854$ & 78.898 & 75,3 & 0 & 0 & 14.900 & 14,2 & 11.031 & 10,5 \\
$1855 / 1859$ & 34.920 & 47,1 & 28.521 & 38,9 & 10.647 & & $14 \%$ & \\
$1860 / 1864$ & 59.320 & 38,6 & 67.677 & 44 & 29.218 & 15,2 & 3.430 & 2,2 \\
$1865 / 1869$ & 87.940 & 50,1 & 45.535 & 25,9 & 36.665 & 20,9 & 5.416 & 3,1 \\
$1870 / 1874$ & 158.636 & 51,9 & 118.985 & 38,9 & 24.436 & 8 & 3.630 & 1,2 \\
$1875 / 1879$ & 218.879 & 52,9 & 162.847 & 39,4 & 30.679 & 5,9 & 7.615 & 1,8 \\
$1880 / 1883$ & 335.643 & 50,1 & 310.887 & 46,4 & 8.297 & 1,3 & 14.671 & 2,2 \\
$1885 / 1888$ & 482.422 & 60 & 289.544 & 36 & 28.475 & 2,6 & 10.521 & 1,4 \\
\hline
\end{tabular}

La transferencia de las aduanas produjo un derrumbe de la recaudación impositiva del que la provincia tardó en recuperarse. Recién a partir de 1863 los ingresos tributarios crecieron en forma sostenida y sólo a fines del decenio alcanzaron niveles similares a la etapa previa a la cesión de las aduanas. Debido a la fuerte caída de las entradas impositivas durante las décadas de 1850 y 1860 cobraron particular importancia las otras fuentes de ingreso. Desde 1859 la venta de tierras fiscales pasó a formar parte de las entradas regulares y durante los tres primeros años de su aplicación representó el principal recurso con que contó el gobierno. Los subsidios de la Nación tuvieron gran significación en años de crisis política (1853-1855, 1862 y 1865-1868) en los que el gobierno nacional otorgó aportes extraordinarios para sostener a las autoridades locales. A principios de la década de 1870 se completó en líneas generales la reorganización del sistema hacendístico. Como resultado de ello, en ese decenio y en el siguiente crecieron en forma sostenida los ingresos provenientes de la recaudación impositiva y la venta de tierras. En conjunto ambas fuentes de renta aportaban entre el $90 \%$ y el 95\% de 
los ingresos totales de la provincia. En contraste, en esta nueva etapa el otorgamiento de subsidios fue más regular pero el monto acordado tendió a decrecer por lo que su participación en la recaudación total fue cada vez más reducida.

\section{Los impuestos (ver cuadro III en el anexo)}

El sistema impositivo correntino en la etapa previa a la organización nacional se originó a fines del siglo XVIII cuando gracias a la expansión de la cría de ganado vacuno el distrito se integraba estrechamente con el mercado de Buenos Aires como proveedor de cueros, de otros subproductos pecuarios y de frutos agrícolas de clima subtropical y sus elaboraciones. En esa etapa de crecimiento económico la administración borbónica sistematizó los impuestos a las actividades productivas y comerciales que luego continuaron aplicando los gobiernos provinciales aunque con considerables reformas. Los impuestos aduaneros se derivaban de la alcabala, derecho del $4 \%$ sobre el valor de las transacciones. En la etapa provincial el impuesto original se multiplicó en una multitud de gravámenes sobre las importaciones y las exportaciones. ${ }^{19}$ Las Patentes comenzaron a percibirse en 1801 y gravaban las actividades lucrativas. Desde 1831 incluyeron tiendas, almacenes, curtiembres, alambiques y hornos de ladrillo, los negocios más importantes de esa época. Los Derechos Policiales eran los antiguos propios del Cabildo que pasaron al Estado provincial y se aplicaban especialmente al comercio de frutos que se desarrollaba en el ámbito urbano. Por su parte, la venta del papel sellado se inició en la jurisdicción correntina en $1774 .^{20}$

La pérdida de los derechos aduaneros en 1855 requirió la reconstrucción del sistema impositivo. Ésta se desarrolló principalmente entre 1856 y 1869 años en que se introdujeron reformas fundamentales a los derechos existentes y se establecieron nuevos impuestos. De estos últimos los más significativos para las finanzas fueron la Contribución Directa (1857) y las Guías de Hacienda (1868). ${ }^{21}$

La Contribución Directa fue un resultado inmediato de la reforma fiscal que resultó de la organización del país. De acuerdo con el artículo 4ํㅜ con la Constitución Nacional la recaudación de este gravamen era prerrogativa de la Nación. No obstante, por decreto del 30 de noviembre de 1854 su percepción fue otorgada a las provincias como subsidio para compensarlas por la pérdida de la renta aduanera. Su aplicación constituía sin duda una reforma radical dado que aspiraba a reemplazar el antiguo sistema fiscal basado en gravámenes al consumo por otro

19 Tras la nacionalización de las aduanas la alcabala continuó cobrándose hasta 1869 como impuesto a las transacciones internas.

20 Otro impuesto de origen colonial era el diezmo que gravaba la décima parte de las cosechas y del procreo del ganado. Dejó de percibirse en 1841 para aliviar a los productores durante guerra contra Rosas.

21 Además se crearon los siguientes impuestos: sobre las herencias ( 8 de julio de 1856), una tasa por el registro de marcas de hacienda ( 16 de julio) y el derecho de laudemio sobre las transferencias de las concesiones de tierras en enfiteusis. A partir del funcionamiento de la Mesa Topográfica (abril de 1861) se cobró un derecho por el examen de las mensuras. Por ley de 4 de abril de 1861 se creó un impuesto por arroba la yerba mate que se extraía de los montes naturales del Misiones. 
fundado en imposiciones al patrimonio. En la provincia, tras algunas demoras comenzó a percibirse a partir de la aprobación de la ley del 12 de febrero de $1857 .^{22}$ Esta primera disposición establecía un derecho del 4\%o sobre los capitales declarados desde los $\$ 1.000$ en adelante. Se incluían los terrenos rurales y urbanos de propiedad particular y los capitales en giro de "negociantes, hacendados, saladeristas y demás capitalistas". Posteriormente, ley del 19 de enero de 1860 amplió la base imponible al incluirse los capitales particulares a partir de los $\$ 500 .{ }^{23}$ En la década de 1870 el impuesto sobre los “capitales en giro" se convirtió de hecho en un gravamen sobre las existencias ganaderas. Las dificultades para determinar el valor de los inmuebles y la cantidad de ganado perjudicaron la recaudación por lo que durante varios años se ensayaron diversos cambios. ${ }^{24}$ Finalmente, a partir de 1884 y por el resto de la década se estableció un derecho de $5 \%$ o sobre el valor de inmuebles y ganados. En el primer caso quedaban exentos los propietarios de predios de hasta $\$ 500 \mathrm{y}$, en el segundo, quienes contasen hasta cien cabezas vacunas y no poseyeran otro capital o industria.

La ley de Guías de Hacienda del 25 de abril de 1868 determinaba el cobro de un derecho por cada cabeza que integrara las tropas que se formaban para la venta dentro o fuera de la provincia. La medida buscaba obtener recursos del creciente consumo de hacienda en la provincia y del comercio de exportación de ganado en pie hacia los distritos vecinos. Este nuevo rubro creció como resultado de la demanda de los saladeros de Entre Ríos y Sur del Brasil y por el repoblamiento ganadero del Paraguay tras la guerra de la Triple Alianza. En la segunda mitad del siglo XIX el valor de las exportaciones de ganado superó ampliamente al de la venta de cueros y otros frutos. ${ }^{25} \mathrm{El}$ activo tráfico permitió sucesivos incrementos entre 1869 y 1885 por lo que en ese último años el impuesto por cada vacuno, caballar y mular era cuatro veces superior al establecido inicialmente. ${ }^{26} \mathrm{La}$ ley referida a la venta de ganado se complementó con otra de 1880 que fijaba derechos sobre la comercialización algunas producciones locales. (cueros, lana, crin y cortes de madera). ${ }^{27}$

En cuanto a los impuestos preexistentes, los cambios de mayor trascendencia correspondieron a las Patentes que en esta etapa crecieron en importancia como fuente de ingreso. La ley del 11 de septiembre de 1863 reclasificó los negocios y creó nuevas categorías de actividades sujetas al gravamen con el fin adaptar

22 R. O. Años 1857-1859, Corrientes, Imprenta Oficial, tomo VIII, p. 386.

23 R. O. Año 1860, Corrientes, Sánchez Negrete, 1886 pp. 23-25.

24 Entre 1876 y 1879 se suprimió la Contribución por cabeza de ganado a cambio de un aumento del derecho de Guías de Hacienda que gravaba las ventas, más fáciles de controlar. Las leyes de 1880 a 1882 redujeron el impuesto a los inmuebles al medio por mil del valor pero incluyeron a todas las propiedades urbanas y rurales, cualquiera fuera su tasación.

25 Exportaciones de ganado en pie: 1864 : vacunos 83.718 , equinos: 15.271 , mulas: $3.695 ; 1875$ : vacunos: 128.545; equinos 16.543; mulas: 1.049; 1888: vacunos: 161.051, caballares, 16.183; mulas: 1.656

26 En 1869 el derecho por la venta de vacunos, caballos y mulas era de 12,5 centavos, entre 1876 y 1881 osciló, según los años, entre 25 y 30 centavos y a partir de 1882 creció a 50 centavos.

27 El impuesto de Guías era de dudosa constitucionalidad porque gravaba el comercio interprovincial y las exportaciones. Sin embargo, no se tiene constancia de que haya habido reclamos por parte de los particulares o del gobierno nacional. Por otra parte, la disposición correntina no era excepcional porque otras provincias adoptaron medidas similares con sus producciones locales. 
percepción del impuesto a los cambios que habían producido en la actividad comercial y productiva. ${ }^{28}$ Desde esa reforma inicial y hasta 1873 se introdujeron nuevas modificaciones que incrementaron los montos por pagar, ampliaron el número de contribuyentes y diversificaron las categorías de negocios.

Cuadro 5. Participación proporcional de los diferentes impuestos en la recaudación total de cada período.

\begin{tabular}{ccccccccc}
\hline Período & Aduanas & $\begin{array}{c}\text { Cont. } \\
\text { Directa }\end{array}$ & Patentes & $\begin{array}{c}\text { Guías } \\
\text { Hacienda }\end{array}$ & $\begin{array}{c}\text { Guías } \\
\text { Frutos }\end{array}$ & Sellados & $\begin{array}{c}\text { Policiales/ } \\
\text { Muni- } \\
\text { cipales }\end{array}$ & Otros \\
\hline $1850 / 1854$ & 59,4 & - & 5 & - & - & 2,6 & 0,9 & 0,3 \\
$1855 / 1859$ & 6,8 & 10,8 & 12,3 & - & - & 3 & 10,5 & 1,5 \\
$1860 / 1864$ & - & 14,6 & 11,1 & - & - & 2,8 & 5,2 & 2,7 \\
$1865 / 1869$ & - & 16,4 & 16,5 & 2,4 & - & 4 & 6,4 & 3,3 \\
$1870 / 1874$ & - & 14,5 & 15,3 & 6,8 & - & 4,2 & 2,9 & 4 \\
$1875 / 1879$ & - & 11,9 & 16,5 & 13,9 & - & 4 & 1,6 & 4,5 \\
$1880 / 1883$ & - & 11,1 & 14,4 & 12,5 & 2,2 & 3,6 & 4,9 & 2,1 \\
$1885 / 1888$ & - & 18,9 & 13,5 & 13,1 & 2,7 & 4,4 & 3,8 & 5,5 \\
\hline
\end{tabular}

En el nuevo ordenamiento fiscal se preveía que la Contribución Directa reemplazara a los derechos aduaneros. En la práctica si bien el impuesto a la propiedad pasó a ser un componente fundamental, en general, la recaudación siguió dependiendo en gran medida de derechos al comercio y la producción. La reestructuración inicial del sistema impositivo produjo mediocres rendimientos por lo que en el quinquenio de 1855-1859 la recaudación de la Contribución Directa y las Patentes fue similar a la de los Derechos Policiales, hasta ese momento un recurso menor. En la década de 1860 se afianzó el aporte de la Contribución Directa y de las Patentes por los cambios introducidos a esos impuestos. Sin embargo, a fines del decenio la recaudación de la Contribución Directa tendió a estabilizarse y se mantuvo sin mayores cambios a lo largo de la década de 1870. Este estancamiento se atribuía a la alta evasión. Por el contrario, los ingresos de las Patentes, que en su mayoría gravaban actividades urbanas más fáciles de controlar, aumentaron en forma sostenida. Asimismo, en este mismo período se incorporaron los ingresos de las Guías que también crecieron rápidamente. En el decenio de 1880 la situación se invirtió porque las Patentes y Guías parecieron alcanzar el límite de lo que podía gravarse en ese momento y las entradas tendieron a estancarse. Por el contrario la Contribución Directa creció de manera espectacular, sobre todo en la segunda mitad de la década como resultado de la consolidación del dominio privado del suelo y la valorización de los inmuebles.

28 R.O., Año 1863, p. 95. La ley de 1863 reclasificaba las actividades sujetas al impuesto. La categoría más alta correspondía a los saladeros, graserías y máquinas de vapor. Entre los negocios se mencionan por primera vez las joyerías, cafés, confiterías y fábricas de carruajes. También quedaron sujetos al impuesto los arquitectos, escribanos y agrimensores. Finalmente se incorporaba a quienes desempeñaban trabajos artesanales y servicios urbanos como era el caso de los albañiles, barberos, herreros, carpinteros, sastres, plateros, relojeros, sombrereros, aguateros. Esta inclusión de actividades en pequeña escala no dejó de provocar alguna resistencia. Los negocios de las zonas rurales constituían un caso especial. Un decreto del 7 de septiembre de 1852 anulaba la prohibición, ordenada en 1833, de establecer comercios en zonas rurales por no ser compatible con el principio de libertad de tránsito. La proliferación de los negocios de la campaña provocó reclamos de los comerciantes urbanos quienes se quejaban, entre otras cosas, que los vendedores de las zonas rurales pagaban una patente menor. A partir de la ley de 1863 se exigió a los comercios de la campaña el pago de la categoría más alta de patente y se prohibían además "las pulperías y tiendas volantes en carretas y cargueros." 


\section{La adjudicación de tierras}

A partir de 1856 y hasta fines de la década de 1880 la adjudicación de tierras públicas representó un componente indispensable de los ingresos de la tesorería. El desarrollo ganadero y el avance de la frontera de la ocupación estimulaban la demanda particular de campos fiscales lo que garantizaba al Estado un ingreso más o menos regular mucho más fácil de recaudar que algunos impuestos. Si bien la transferencia de terrenos fiscales al dominio privado se había iniciado en la etapa colonial a mediados del siglo XIX las tierras públicas abarcaban todavía alrededor de 4.000.000 ha. de la jurisdicción. A este extenso patrimonio se agregó a partir de 1856 el control provisorio de la zona de las antiguas Misiones a medida que se arreglaban las disputas fronterizas con el Paraguay. Por más de dos décadas Corrientes administró la comarca pero debió cederla al gobierno de la Nación al crearse el Territorio de Misiones por ley del 22 de diciembre de 1881.

En el momento de la organización nacional el régimen de tierras de la provincia estaba regulado por la ley de enfiteusis del 3 julio de 1830. La misma determinaba que los campos fiscales debían otorgarse en alquiler por un plazo de cincuenta años mediante el pago de un canon anual del $2 \%$ del valor del terreno. ${ }^{29}$ La enfiteusis fue instituida para facilitar la ocupación de la campaña pero a mediados de la década de 1850 era ya obsoleta por la creciente valorización de los terrenos y las necesidades fiscales. No obstante, pese a los reclamos del P.E. la Legislatura tardó en modificar el régimen de tierras debido a la resistencia de los hacendados para quienes la enfiteusis constituía un medio económico para alcanzar la posesión legal del suelo. Las primeras leyes que autorizaron la venta de tierras (6 de octubre de 1856 y 5 de febrero de 1859) fueron de carácter extraordinario y no anularon la enfiteusis como ley general (Cárcano, 1972: cap. XVIII). Recién tras varios intentos infructuosos el 25 de agosto de 1864 se aprobó un nuevo régimen basado en la venta y el arrendamiento por ocho años. Finalmente, con la ley del 17 de septiembre de 1869 quedó consagrada la venta como única forma de adjudicación. La vigencia de esta medida aceleró la enajenación de las tierras públicas pero las facilidades que introdujo (el pago en diez cuotas) no fueron suficientes para las necesidades fiscales por lo que se dictaron varias leyes especiales. Entre éstas se destacaron la del 14 de octubre de 1879 y del 22 de junio de 1881. La primera facultaba al P.E. a vender cien leguas cuadradas por la mitad de su valor con la condición de que el comprador abonara al contado. Por su parte la ley del 22 de junio de 1881 autorizó la venta masiva de las tierras de Misiones (unas 2.000.000 ha repartidas entre 27 compradores) ante la proximidad de la transferencia de la comarca a la jurisdicción nacional. ${ }^{30}$ Finalmente, la existencia de diversas disposiciones sobre venta de tierras concluyó con la promulgación de la ley

29 La percepción del canon se había suspendido a mediados de 1844 pero se restableció a fines de 1855 . Además en ese año se cumplieron los veinticinco años de vigencia de la enfiteusis y tal como establecía la ley, se hizo una nueva tasación de los terrenos para actualizar los valores.

30 La ley de venta de las tierras misioneras incorporaba las ventajas de las leyes de 1869 y 1879 ya que los interesados abonaban la mitad del precio si adquirían al contado y en diez cuotas si lo hacían a plazos. Además no se requería la mensura del campo. 
del 1o de octubre de 1883 que fijaba plazos estrictos para la realización de los trámites de la denuncia y adoptaba providencias para evitar la adjudicación de áreas ya concedidas.

Los montos percibidos por la adjudicación de tierras fiscales por lo común superaban a lo que se obtenía por cualquiera de los impuestos en forma individual y, durante algunos años, fueron mayores a los ingresos tributarios en su conjunto. Sin embargo, era evidente que se trataba de un recurso en pocos años se agotaría. Por un tiempo el Estado conservó la propiedad de parte de las tierras adjudicadas al otorgarlas en enfiteusis o arrendamiento pero con la supresión del alquiler en 1869 esta participación disminuyó a medida vencían los contratos y las tierras se ofrecían a la venta. ${ }^{31}$ El proceso de transferencia se completó en la segunda mitad de la década de 1880. De acuerdo con un catastro de 1894 las áreas fiscales comprendían alrededor de 800.000 ha. que se ubicaban casi en su totalidad en la cuenca del Iberá, zona inundable de difícil acceso en el centro de la provincia.

La rápida enajenación que tuvo lugar entre 1856 y 1889 dio lugar más tarde a críticas sobre la falta de previsión del Estado para reservar su patrimonio inmobiliario para la colonización agrícola. En el momento en que produjeron las ventas, sin embargo, existía la convicción de que la entrega de tierras al dominio particular fortalecía la industria pastoril e incrementaba la riqueza. ${ }^{32}$ Mayor preocupación despertaba el destino de los ingresos. Dado que las enajenaciones estaban afectadas, en porcentajes variables según las leyes, al pago del capital y los intereses de la deuda pública sólo una parte del producto de las ventas ingresaba como dinero efectivo para los gastos generales de la administración. En varios mensajes del P.E. se señaló que de esta forma la provincia enajenaba su patrimonio para cubrir deudas que en su mayor parte se originaron en los conflictos facciosos del período. ${ }^{33}$ Otro aspecto que preocupaba era la fuerte dependencia en un recurso que terminaría por extinguirse. Existía la convicción de que la venta de tierras debía ser un expediente provisorio hasta que el crecimiento de los ingresos impositivos permitiera cubrir las necesidades de la administración. Sin embargo, pese a los avances logrados en la recaudación tributaria esta expectativa estuvo lejos de cumplirse por lo era de preverse una crisis fiscal una vez que declinara la venta de terrenos.

31 La proporción de las entradas por enfiteusis y arrendamiento en el total de los ingresos de tierras fue: 1855-1859: 34\%; 1860-1864: 18,2\%; 1865-1869: 32,5\%; 1870-1874: 15\%; 1875-1879: 5,7\%. Los últimos registros de ingresos por alquiler de tierras fiscales son de 1883.

32 Salvo el caso excepcional de la venta de Misiones por lo común los campos se enajenaron en unidades de 2.700 ha a 10.800 ha, aunque también una pequeña proporción se destinó para pueblos y colonias agrícolas.

33 Los poseedores de los títulos de deuda que se emitieron entre 1863 y 1883 podían utilizarlos para la adquisición de tierras. Así, por ejemplo en 1870 del total de $\$ 73.582$ recaudado en concepto de venta de tierras, sólo el $25 \%$ era dinero en efectivo.; en 1873 , de $\$ 142.809$, el porcentaje fue del $35 \%$ y en 1874 , de \$176.149, la proporción alcanzó al 36\%. 


\section{Subsidios nacionales y rentas eventuales}

Las rentas eventuales provenían de multas, sucesiones vacantes, venta y alquiler de bienes del Estado (excepto tierras), devoluciones de adelantos, etc. Por su misma naturaleza la recaudación era muy variable aunque en general su participación dentro del conjunto de las entradas era bastante reducida. Solamente durante la década de 1850 tuvieron un peso considerable porque el gobierno provincial debió recurrir a diversos expedientes para obtener recursos hasta que se organizara el sistema rentístico. ${ }^{34}$

Con respecto a los subsidios, la Constitución nacional establecía que las provincias podían recibir ayuda de la Nación en caso de que sus recursos resultaran insuficientes para sostener su administración (art. 69). Esta ayuda podía consistir en aportes regulares para cubrir gastos corrientes o específicos y también en contribuciones extraordinarias para atender emergencias de diverso tipo. Los aportes nacionales sólo tenían un carácter complementario a los ingresos provinciales pero durante las etapas iniciales de la organización nacional fueron una ayuda fundamental para el funcionamiento de los gobiernos locales.

Los primeros auxilios que recibió Corrientes entre 1852 y 1855 respondieron a medidas excepcionales que no estaban reguladas por ninguna disposición. ${ }^{35}$ Recién por la ley del 24 de septiembre de 1857 la Nación otorgó un subsidio regular a las provincias para subvencionar la instrucción primaria (República Argentina, 1883: 49). Existen constancias de que Corrientes recibió este auxilio durante 1858 y 1859. En el interregno institucional que se produjo tras la batalla de Pavón la provincia pudo acceder nuevamente a los recursos de las aduanas fluviales a los que se agregaron remesas especiales del gobierno de Buenos Aires. ${ }^{36}$ A partir de la presidencia de Bartolomé Mitre el gobierno nacional pudo acudir regularmente en auxilio de las provincias. En 1863 para cada una se incluyó en el presupuesto un subsidio de mil pesos mensuales para gastos generales. Asimismo, por una resolución de mayo de 1867 se otorgó a Corrientes y otras provincias un subsidio anual de dos mil pesos para subvencionar la instrucción primaria. Junto con estos aportes regulares, por ley del 4 de octubre de 1865 Corrientes recibió una asistencia extraordinaria en consideración de las dificultades para percibir sus rentas a raíz de la invasión paraguaya. Este auxilio se mantuvo hasta fines de 1867. Otra ayuda excepcional fue la ley del 23 de agosto de 1863 por la cual la Nación destinaba \$16.000 anuales para retirar de circulación el papel

34 Una medida de gran significación simbólica fue la ley del 10 de diciembre de 1852 declaró nulas las confiscaciones por delitos políticos. De esta forma, el estado provincial renunciaba expresamente a utilizar mecanismos de coerción para obtener recursos extraordinarios.

35 En 1852 José Urquiza en su calidad de Director Provisorio de la Confederación entregó a la provincia poco más de $\$ 53.000$ "en remuneración de los gastos hechos en la campaña contra D. Juan Manuel de Rosas". Asimismo, mientras la provincia administró las aduanas nacionalizadas el gobierno local utilizó parte de los fondos del gobierno federal para financiar movilizaciones extraordinarias.

36 De acuerdo con las cuentas del Administrador de Aduanas designado por la provincia, entre diciembre de 1861 y el 31 de agosto de 1862 se utilizaron $\$ 81.803$ del fondo nacional para sostener las milicias movilizadas por el gobierno de Corrientes en favor de la causa liberal. Con los aportes independientes remitidos desde Buenos Aires la suma total recibida por Corrientes hasta fines de 1862 era de alrededor de cien mil pesos. Archivo General de la Provincia de Corrientes Expedientes Administrativos, legajo no 137; Bartolomé Mitre a Manuel Lagraña, 27 de febrero de 1863, Archivo Mitre, T. XXV, pp. 133-136. 
moneda de la provincia (República Argentina 1884a: 44 y 225). ${ }^{37}$ Durante la década de 1870 se ampliaron considerablemente las partidas específicas destinadas a la educación en las provincias (ley del 25 de septiembre de 1871), también se estableció un fondo para la creación de bibliotecas populares (ley de 21 de septiembre de 1870) que se mantuvo hasta 1879 (República Argentina 1884b: 95 y 194). En contraste, el subsidio nacional destinado a rentas generales dejó de pagarse a partir de 1877 por los recortes en el presupuesto que generó la crisis económica iniciada en 1873. En lo que respecta a los aportes extraordinarios, durante algunos años (1869, 1873 y 1874) el gobierno de la provincia recibió fondos para mantener la vigilancia frontera con Entre Ríos y prevenir rebeliones internas debido a los levantamientos de López Jordán. En la década de 1880 ya no hubo aportes extraordinarios y los subsidios regulares sólo se destinaron al fomento instrucción primaria.

\section{Organización nacional y funciones de gobierno}

En la etapa previa a la organización nacional la función prioritaria del Estado provincial era el mantenimiento del orden interno y la defensa del territorio. Aún en tiempo de paz la mayor parte del gasto público se destinaba al sostenimiento de una fuerza militar permanente y a las milicias movilizadas. Hasta $1853 \mathrm{el}$ ramo de Guerra absorbió regularmente alrededor del 60\% de las erogaciones del Estado correntino. ${ }^{38}$

La organización federal del país introdujo modificaciones en la estructura del gasto. La pérdida de los ingresos aduaneros con el tiempo quedó ampliamente compensada con la creación una autoridad nacional que, con mayores recursos, asumió gran parte de las funciones que hasta ese momento estaban a cargo de las provincias. Posiblemente el beneficio más inmediato fue el traspaso de las obligaciones militares con la creación de un ejército nacional. Asimismo, debido a la mayor disponibilidad de fondos las grandes inversiones públicas necesarias para el desarrollo y la integración económica del país (ferrocarriles, caminos, puentes, puertos, telégrafos, inmigración) quedaron, en la práctica, bajo la responsabilidad prioritaria del gobierno federal. Aún en el caso de la instrucción primaria que incumbía sobre todo a las provincias los logros dependieron del apoyo permanente de la Nación. La transferencia de funciones de la provincia a la esfera nacional se vio acompañada también por el traspaso del gobierno de los centros urbanos a las municipalidades. Estos organismos, junto con las entidades de beneficencia, además tenían la responsabilidad prioritaria sobre los temas vinculados con la salud pública y la asistencia social.

37 Esta operación se completó en 1869.

38 A principios de la década de 1850 los gastos se clasificaban en cuatro ramos: Gobierno (Poder Ejecutivo, Legislatura y jueces), Hacienda (Colecturía, instrucción pública, correos y policía) Guerra (fuerza veterana y milicias) y Extraordinarios (obras públicas, fiestas cívicas, compras de armas y vestuario, abasto de la tropa). 
Con estos cambios la inversión de los fondos provinciales se orientó a la modernización de la estructura estatal, el fortalecimiento de la seguridad interna y el impulso de la instrucción primaria. En el área de la administración gubernamental los presupuestos destinaban partidas específicas para los poderes Legislativo y Judicial, en cuanto al Ejecutivo, las sumas se distribuían en los rubros correspondientes a despacho del Gobernador y los ministerios de Gobierno y Hacienda. En lo que respecta a la defensa y seguridad la reforma militar implicó que el mayor peso de estas funciones pasaba a la esfera civil mediante la organización de una fuerza policial. No obstante, las provincias no perdieron totalmente su injerencia en los asuntos militares porque participaban en la formación de la fuerza de reserva del ejército o Guardia Nacional y designaban a quienes ejercerían el comando de la misma. Asimismo hasta 1880 los gobiernos de provincia reclamaron la atribución de formar una fuerza militar permanente sostenida con recursos locales (Auza, 1971: Cap. I). De esta forma los gastos para defensa y seguridad se repartían entre los que se asignaban a la Policía de la Capital, la Administración Departamental (policía rural), la fuerza militar y el abasto. ${ }^{39}$ Un cambio de gran importancia fue la incorporación en el presupuesto de un rubro específico destinado a la instrucción pública. El cálculo anual se completaba con pequeñas partidas destinadas a obras públicas, pensiones y subvenciones y desembolsos eventuales.

Cuadro 6. Gasto presupuestado y gasto real (promedio anual)

\begin{tabular}{cccc}
\hline Período & Gasto presupuestado & Gasto real & Diferencia (\%) \\
\hline $1856-1859$ & 143.391 & 118.052 & $-17,7$ \\
$1860-1864$ & 151.257 & 160.300 & 6 \\
$1867-1870$ & 248.465 & 274.944 & 10,7 \\
$1873-1877$ & 376.306 & 441.403 & 17,3 \\
$1878-1881$ & 546.396 & 636.801 & 16,5 \\
$1882-1885$ & 684.104 & 779.827 & 14 \\
$1886-1889$ & 839.522 & 1.361 .119 & 62,1 \\
\hline
\end{tabular}

Pese a que la inversión de los fondos estaba regulada por el presupuesto con frecuencia el gasto real no se ajustaba a lo establecido en el cálculo. Los primeros presupuestos de fines de la década de 1850 fueron muy optimistas en cuanto a la obtención de recursos por lo que, en la práctica, el gasto real fue inferior a lo estimado. A partir de la década de 1860 los egresos superaron a los cálculos aunque la ampliación del gasto estaba muy condicionada por la escasez de ingresos genuinos y el limitado acceso al crédito. Las diferencias, a veces muy importantes, que se produjeron durante algunos años eran compensadas en los ejercicios siguientes. En consecuencia, si se considera el acumulado de varios años la diferencia entre el gasto presupuestado y el real no fue tan grande hasta segunda mitad de la década de 1880 .

39 De acuerdo con su organización y funciones la fuerza militar estaba destinada a prevenir amenazas contra la estabilidad del gobierno o la integridad territorial mientras que la policía debía preservar el orden social y perseguir el delito. En la práctica con frecuencia la Guardia Nacional movilizada cumplía funciones policiales y se comisionaba a jefes militares para que se hicieran cargo de la fuerza policial en los departamentos donde crecía la inseguridad. 


\section{Composición del gasto público (cuadro IV del anexo)}

Al iniciarse la organización nacional la estructura del Estado correntino era sumamente rudimentaria. La fuerza militar era la entidad más desarrollada mientras que la administración civil constituía un plantel reducido. Como corolario, el desempeño de ciertas funciones básicas dependía de las prestaciones más o menos voluntarias de los habitantes. Por ese motivo uno de los objetivos prioritarios del nuevo ordenamiento institucional fue la modernización de la estructura estatal con reparticiones de gobierno de funcionamiento regular, oficinas especializadas y personal estable y profesionalizado. Las reformas de este período aunque de alcance limitado constituyeron avances en favor de una mayor institucionalización de la labor del Estado.

En lo que se refiere a los órganos superiores del gobierno provincial desde 1856 se amplió el número de diputados y el período sesiones. Por primera vez se estableció un Tribunal Superior de Justicia con carácter permanente y se crearon juzgados de primera instancia en la capital y el interior. Otro hecho significativo fue que en la década de 1880 los juzgados ya estaban a cargo de letrados. En el ámbito del Poder Ejecutivo la antigua Secretaría del gobernador se dividió en los ministerios de Gobierno y Hacienda. Se amplió considerablemente el aparato de recaudación mientras que en la esfera del Ministerio de Gobierno se crearon nuevas oficinas. ${ }^{40}$

Cuadro 7. Participación porcentual en el gasto de las áreas de Gobierno y Hacienda (promedio del período)

\begin{tabular}{ccccc}
\hline Período & Legislatura & Poder Ejecutivo & Poder Judicial & Hacienda \\
\hline $1850 / 1854$ & & 24,2 & & 11,5 \\
$1855 / 1859$ & 4,9 & 25,1 & 12,1 & 8,3 \\
$1860 / 1864$ & 4,3 & 13,5 & 7 & 6 \\
$1865 / 1868$ & 1 & 14,7 & 6,1 & 2,5 \\
$1870 / 1874$ & 3,3 & 10,6 & 5,1 & 5,2 \\
$1875 / 1879$ & 2,5 & 11,5 & 4,9 & 7,2 \\
$1880 / 1883$ & 2,7 & 10,3 & 3,6 & 5,5 \\
$1885 / 1887$ & 3,2 & 9,7 & 3,1 & 6,2 \\
\hline
\end{tabular}

Los egresos en esta área del Estado tradicionalmente constituían uno de los rubros que experimentaban menos fluctuaciones dado que se trataba de reparticiones clave para la actividad gubernativa y su personal gozaba de más estabilidad que el resto de la administración. Pese a que la inversión fue creciendo a partir de 1870 su participación relativa dentro del total disminuyó a medida que se ampliaban otros sectores de la acción estatal. ${ }^{41}$

40 La Oficina de Estadística (1883) y la Dirección de Tierras y Colonias (1883) y el Archivo General.

41 El personal de los poderes legislativo y judicial y la administración central de la provincia en 1859 sumaba en total 91 empleados y funcionarios que representaban el 25\% del total de la administración. Hacia 1888 llegaban a 140 y constituían el $8 \%$ del personal estatal. No obstante, esta área incluía el sector más jerarquizado por lo que en ese último año representó el $28 \%$ del gasto provincial. 
La defensa y seguridad interior fueron áreas prioritarias de la acción de gobierno, sin embargo, durante los primeros años de la etapa constitucional fueron los sectores que tuvieron los mayores recortes. En 1854 se produjo la desmovilización de las fuerzas militares de la provincia (cuyos jefes y oficiales pasaron a la nómina Nacional) pero la medida no fue acompañada por un crecimiento proporcional de la policía. No obstante a partir de la década de 1860 la inversión destinada a las fuerzas de policiales y militares volvió a crecer.

Cuadro 8. Participación porcentual de los rubros de Seguridad y Defensa en el gasto de la provincia (promedio del período).

\begin{tabular}{ccccc}
\hline Período & Fuerza militar & $\begin{array}{c}\text { Policía de la } \\
\text { ciudad de } \\
\text { Corrientes }\end{array}$ & Departamentos & Abasto \\
\hline $1850 / 1854$ & 53,9 & 1 & - & - \\
$1855 / 1859$ & 4,1 & 9,2 & 7,3 & 2,6 \\
\hline $1860 / 1864$ & 12,1 & 7,4 & 16,6 & 6,2 \\
\hline $1865 / 1868$ & 25,5 & 4,4 & 26,4 & 7,5 \\
$1870 / 1874$ & 15,5 & 3,1 & 18,7 & 11,9 \\
$1875 / 1879$ & 13,1 & 4,3 & 15,9 & 15,8 \\
$1880 / 1883$ & 6 & 2,1 & 13 & 18,3 \\
$1885 / 1887$ & 3,2 & 3,3 & 12,5 & \\
\hline
\end{tabular}

Los gastos militares variaban mucho de un año a otro. Luego de la desmovilización de 1854 no volvió a crearse un cuerpo militar permanente hasta 1868. Una vez restablecida, esta fuerza veterana funcionó hasta 1885 pero rara vez demandaba más 5\% del gasto total. Sin embargo, las movilizaciones temporarias de la Guardia Nacional para afrontar las frecuentes crisis bélicas producían gastos fuera de presupuesto que durante algunos años representaron una alta proporción de los egresos provinciales. ${ }^{42}$ En contraste, el gasto correspondiente a la fuerza policial tendía a ajustarse con lo establecido en el presupuesto. En el lapso de 1855 a 1861 los gobiernos fortalecieron las fuerzas policiales de las ciudades de Corrientes y de Goya pero relegaron a los departamentos de la campaña. En ellos el servicio dependió de la cooperación de los ciudadanos enrolados en la Guardia Nacional. Recién a partir de 1863 se estableció como prioridad el crecimiento de la fuerza policial en el interior con el aumento de agentes rentados. Desde ese año la inversión de fondos creció en forma sostenida y como consecuencia de ello, pasó a ser el área de gobierno que incluía el personal más numeroso. ${ }^{43}$ Finalmente, otro aspecto vinculado con el gasto en seguridad y defensa es el del abasto de las tropas. Desde mediados de la década de 1870 se produjo un fuerte crecimiento en este rubro hasta superar a los que correspondían a los salarios de los agentes. Esto indica la sistematización de los procedimientos de suministro

42 Participación porcentual de la fuerza militar en el gasto total: 1856: 0,5; 1857: 2,1; 1858: 1,7; 1859 : 12,2; 1860: 0,5; 1861:13,5; 1862: 44,6; 1863: 0,5; 1864: 1,5; 1865-1866: 2,3; 1868: 48,7; 1870: 20,2; 1873: 11,$6 ; 1874: 14,6 ; 1875: 5,2 ; 1876: 5 ; 1877: 4,4 ; 1878: 34,6 ; 1879: 16,5 ; 1880: 15,2 ; 1881: 2,3 ; 1882$ : 3,1; 1883: 3,5; 1886: 2,$6 ; 1887: 0$.

43 En cuanto al personal de defensa y seguridad de acuerdo con el presupuesto de 1859 no había cargos militares, la policía de la ciudad de Corrientes tenía 85 y la administración departamental, 82. En 1869 la guardia militar tenía 142 miembros, la policía de Corrientes, 55 y la de los departamentos, 165. Para 1888, sólo había 4 cargos militares, pero la policía de la capital tenía 372 y la administración departamental, 862. En conjunto estas áreas reunían en ese año el $73 \%$ de empleados y funcionarios de la provincia 
mediante contratos y licitaciones y una mejora en el equipamiento de armas y uniformes para las fuerzas.

En lo que respecta a la instrucción pública durante el período 1852-1861 los gobiernos correntinos destinaron una importante proporción de sus escasos recursos con este fin. Aunque las sumas asignadas eran modestas, en términos relativos la participación en el total de los egresos fue de las más elevadas del siglo XIX. Por el contrario, durante gran parte de la década de 1860 hubo una fuerte orientación de los gastos para la defensa en detrimento de la educación y la obra pública ${ }^{44}$ Recién a partir de la década de 1870 se reanudó el esfuerzo sostenido en el ámbito educativo. A esta mejora contribuyó sin duda la ley nacional del 25 de septiembre de 1871 que creaba un régimen de subsidios que exigía a las provincias una contrapartida de inversiones en el área. La mayor disponibilidad de fondos se tradujo en un moderado crecimiento del número de alumnos y una mayor atención a los temas vinculados con el equipamiento edilicio, la provisión de material escolar y la formación de los preceptores. Además se tomaron medidas para crear un sistema escolar uniforme de alcance provincial. ${ }^{45}$ Pese a estos avances la educación fue el área de gobierno que regularmente experimentaba los mayores recortes ${ }^{46}$

La inversión en obras públicas no formaba parte de los gastos regulares del Estado por lo que las realizaciones dependían sobre todo de la disponibilidad de recursos eventuales. Debido a esta limitación el gasto se destinaba sobre todo a la mejora del equipamiento institucional de la provincia (oficinas, escuelas, juzgados, jefaturas, receptorías). Una de las excepciones fue la creación de pueblos y colonias que tuvo una gran importancia para la ocupación de la campaña. De todas formas salvo algunos momentos excepcionales la obra pública sólo representó una fracción pequeña del gasto total. Recién en la segunda mitad de la década de 1880 se puede apreciar una mayor participación relativa de este rubro. En lo referente a las obras también hay que tener en cuenta la creciente participación del Estado Nacional. Si bien las inversiones de la Nación en Corrientes no pueden comparase con las que se hicieron en otras provincias las mejoras en la infraestructura tuvieron un fuerte impacto local. ${ }^{47}$

44 En 1864 el gobierno provincial decidió transferir las escuelas de la ciudad de Corrientes y de los principales pueblos del interior a las municipalidades recién creadas. La labor de los ayuntamientos fue muy deficiente.

45 De acuerdo con el censo escolar de 1884 asistían a las escuelas públicas y privadas 8.759 alumnos cifra que representaba cerca del $23 \%$ de la población escolar. En el presupuesto de 1885 los cargos para el área de educación, 270 en total, comprendían el 18\% el de los empleos de la provincia. A partir de 1879 todas las escuelas públicas quedaron bajo la dependencia exclusiva del P.E provincial con lo cual se redujo la intervención de los municipios. La reorganización definitiva tuvo lugar con la aprobación de la ley de educación común (1886) y la instalación del Consejo General de educación

46 Gastos presupuestados y egresos reales en educación (promedio anual en pesos): 1856-1859: 21.454/11.903; 1860-1864: 33.500/11.407; 1865-1869: 19.089/1.775; 1870-1874: 46.510/28.288; 1875-1878: 73.560/42.1018; 1880-1884:126.601/77.771; 1885-1887: 151.340/90.070

47 Las obras nacionales más significativas fueron el Colegio Nacional, las líneas telegráficas para Corrientes y las cabeceras departamentales, obras de saneamiento en la capital provincial, los muelles de los puertos de Corrientes y Goya, puentes sobre algunos ríos interiores y la instalación de los primeros tramos del ferrocarril Nordeste Argentino. 


\section{La deuda pública}

Una de las novedades de la administración de las finanzas públicas en la etapa constitucional fue el uso regular del crédito como fuente de financiación. Los presupuestos del período admitían la existencia de un déficit que debía solventarse a través del endeudamiento. En la práctica, regularmente el déficit real era muy superior al estimado y las obligaciones pendientes pesaban de manera creciente en el gasto público. Para los diversos gobiernos el pago de la deuda constituyó una prioridad a la que prestaron especial atención aún a costa de postergar la inversión en otras áreas de la labor estatal

Gráfico 2. Evolución de la deuda pública de la provincia de Corrientes (1855-1887)

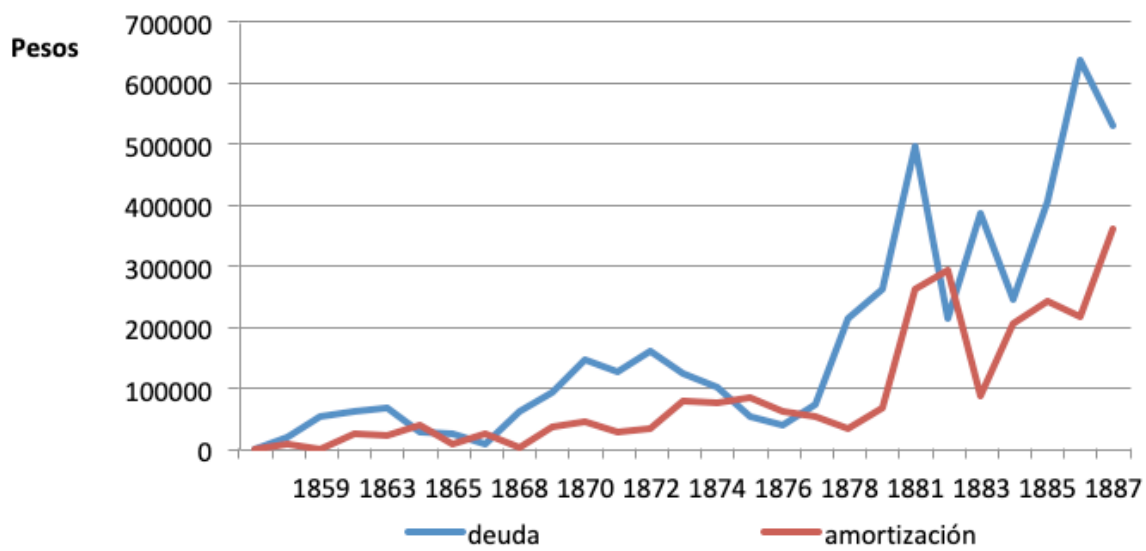

El financiamiento del déficit atravesó por diversas etapas. La primera se extendió desde 1853 hasta 1863. Durante la mayor parte de ese lapso, los déficits se cubrieron con la emisión de papel moneda local y la postergación de los pagos. ${ }^{48}$ A partir de octubre de 1855 se aceleró la emisión de billetes y con ellos se solventaron gran parte de los desequilibrios de los años 1855, 1856 y 1857. Este procedimiento, sin embargo, no podía prolongarse porque el aumento de la cantidad produjo una nueva depreciación del papel moneda. Para fines de la década el dinero local había perdido su utilidad como instrumento de cambio. ${ }^{49}$ Finalmente por la ley del 26 agosto de 1863 el gobierno nacional se hizo cargo del retiro de los billetes.

A partir de la ley del 8 de agosto de 1863 se inició una nueva etapa en la evolución de la deuda pública en la cual procedimiento regular para solventar las obligaciones atrasadas y gastos extraordinarios fue la emisión de títulos de deuda que daban un interés y podían emplearse, en proporción variable, en la compra de tierras. ${ }^{50}$ La primera emisión se estableció para cubrir los compromisos pendien-

48 Debe señalarse que por ley del 2 de diciembre de 1854 el gobierno de la Nación se hizo cargo de las deudas de las provincias contraídas en las luchas por la organización nacional. Así gobierno de Corrientes pudo liberarse de los compromisos pendientes de la lucha contra Rosas.

49 Hacia 1859 circulaban billetes por un valor total de \$1.574.000 pero la cotización en relación con el peso plata había caído de cuatro a uno en 1853, a diez a uno.

50 Entre 1863 y 1883 se emitieron en total 24 series de bonos. Los que entraron en circulación entre 1863 y 1870 pagaban intereses altos a raíz de la inestabilidad del período (entre $12 \%$ y el $18 \%$ anual) y podían utilizarse en la adquisición de tierras públicas hasta dos tercios del valor de los campos. A partir de 1872 la tasa de interés más común fue del 6\% (aunque los bonos de deuda de 1881 pagaron el 12\%) y sólo podían usarse para cubrir la mitad del valor de los terrenos fiscales. 
tes del período 1855-1861, valuados en \$52.000. Esta obligación se redujo rápidamente pero a partir de 1868 la deuda volvió a crecer de manera sostenida hasta 1872 como consecuencia del recrudecimiento de los enfrentamientos civiles. Al finalizar ese año la deuda pública alcanzaba a $\$ 161.500$ equivalente al 58\% de los ingresos. En 1873 se inició un período de mayor estabilidad en el cual gran parte de los recursos fiscales se destinaron a reducir los compromisos. En esta política posiblemente influyó del clima general de austeridad que generaba la crisis económica del país. Hacia 1876 la deuda alcanzó su nivel más bajo, unos \$39.900.

El tercer momento en la evolución de la deuda se inició en 1878. A partir de ese año comenzó un nuevo ciclo de crecimiento que se mantuvo en forma sostenida hasta fines de la década de 1880. El primer impulso estuvo dado por los gastos extraordinarios que generaron la rebelión liberal de 1878-1880. En 1881 la deuda llegó a unos \$512.000 aunque pronto fue cancelada con los fondos de la venta de tierras de Misiones. Sin embargo, pese al retorno de la paz la deuda estatal continuó incrementándose por una política de gasto más expansiva hasta llegar a $\$ 638.000$ hacia 1887 (equivalente a 72\% de los ingresos). La mayor liberalidad en el gasto se debió a que desde 1879 se contaba con los créditos otorgados por la sucursal del Banco Nacional en la ciudad de Corrientes. Los préstamos de la entidad bancaria garantizados por los ingresos por venta de tierras públicas constituyeron un mecanismo mucho más ágil que los bonos. Éstos dejaron de emitirse descle 1883 y los que restaban fueron retirados de circulación en 1886 y $1887 . .^{51}$ Sin embargo, el peso del servicio de la deuda tendió a crecer por la acumulación de obligaciones en concepto de intereses y amortización que producía la renovación sucesiva de los créditos. Para los gobernantes locales este esfuerzo no se traducía en beneficios para la provincia en un momento en que el Estado deseaba cumplir un papel más dinámico en el crecimiento económico. Se consideraba que el instrumento para esta política debía ser la creación de un banco provincial.El proyecto, varias veces planteado recién pudo concretarse en diciembre de 1887 dentro del esquema previsto a nivel nacional por la Ley de Bancos Garantidos. Los recursos del nuevo banco se obtuvieron mediante el primer empréstito externo de $\$ 5.000 .000$ oro contratado con un sindicato de banqueros de París y Londres. Esta enorme deuda superaba las posibilidades de pago con recursos provinciales hecho que resultó evidente al estallar la crisis económica en 1890.

\section{Las finanzas de Corrientes en el contexto nacional}

Las características de la evolución de las finanzas de la provincia de Corrientes se pueden apreciar más claramente si se las examina en relación con el desempeño fiscal de las otras jurisdicciones que integraban la República Argentina.

51 Hacia 1880 el valor de la deuda era de $\$ 263.710$ de los que el 33,5\% correspondía a bonos, el $25 \%$ a préstamos del Banco Nacional y el 41,5\% a libramientos impagos. Para 1883 el monto era de $\$ 387.000$ y la proporción era de 30,4\%,44,3\% y 25,3\%, respectivamente. A principios de 1887 la deuda sumaba $\$ 637.705$ de los que el $91,7 \%$ provenía de préstamos del banco, el 2,9\% de los bonos y el 5,4\% de libramientos. 
Cuadro 9. Recaudación media de las provincias argentinas (en pesos moneda nacional) ${ }^{52}$

\begin{tabular}{ccccccc}
\hline & $1851 / 1852$ & $1856 / 1859$ & $1868 / 1871$ & $1875 / 1879$ & $1880 / 1884$ & $1885 / 1886$ \\
\hline Santa Fe & $43.000(\mathrm{a})$ & 95.000 & 252.200 & 375.000 & 877.500 & 1.436 .894 \\
Entre Ríos & $\dot{c} 180.000 ?$ & $\mathrm{~s} / \mathrm{d}$ & $\mathrm{s} / \mathrm{d}$ & 863.400 & 1.280 .000 & 1.193 .834 \\
Corrientes & $\mathbf{1 2 0 . 9 0 0}$ & $\mathbf{7 7 . 6 0 0}$ & $\mathbf{2 2 7 . 7 0 0}$ & $\mathbf{4 1 7 . 0 0 0}$ & $\mathbf{5 9 9 . 0 0 0}$ & $\mathbf{6 5 2 . 6 0 0}$ \\
Córdoba & 197.000 & 76.200 & $148.000^{*}$ & 288.300 & 400.200 & 729.400 \\
Tucumán & $\dot{2} 28.500 ?$ & 32.700 & 55.500 & 113.700 & 184.500 & 384.300 \\
Salta & $\mathrm{s} / \mathrm{d}$ & $\mathrm{s} / \mathrm{d}$ & $\mathrm{s} / \mathrm{d}$ & $\mathrm{s} / \mathrm{d}$ & $\mathrm{s} / \mathrm{d}$ & 262.700 \\
Santiago & $\mathrm{s} / \mathrm{d}$ & $\mathrm{s} / \mathrm{d}$ & $57.300^{*}$ & 56.500 & 93.000 & 163.805 \\
del Estero & $\mathrm{s} / \mathrm{d}$ & $\mathrm{s} / \mathrm{d}$ & $49.000^{*}$ & 96.600 & 168.500 & 88.925 \\
Catamarca & $\mathrm{s} / \mathrm{d}$ & $\mathrm{s} / \mathrm{d}$ & $38.300^{*}$ & 50.600 & 64.600 & 92.300 \\
La Rioja & 28.000 & $\mathrm{~s} / \mathrm{d}$ & $71.500^{*}$ & 42.000 & 73.700 & 67.452 \\
Jujuy & $\mathrm{s} / \mathrm{d}$ & $\mathrm{s} / \mathrm{d}$ & $49.000^{*}$ & 76.200 & 133.100 & 155.800 \\
San Luis & 56.600 & $\mathrm{~s} / \mathrm{d}$ & 64.600 & 105.100 & 125.600 & 238.300 \\
Mendoza & s/d & $172.800^{*}$ & 187.300 & 163.500 & 288.000 \\
San Juan & 43.000 & $\mathrm{~s}$ & & & \\
\hline a) Corresponde al año $1848 ;{ }^{*}$ Recursos presupuestados & & & &
\end{tabular}

Como es sabido, existió una brecha muy grande entre los recursos del gobierno nacional, los de Buenos Aires y los del resto de los estados provinciales. ${ }^{53}$ Asimismo, dentro del grupo de provincias menos favorecidas había también notables diferencias en cuanto a su capacidad de recaudación. En la etapa previa a la organización nacional las provincias de Corrientes, Entre Ríos y Córdoba contaban ingresos aduaneros superiores a los del resto de las provincias. Consecuentemente, estas jurisdicciones fueron las más afectadas por la nacionalización de las aduanas. Superada crisis resultante de las reformas fiscales, en general todas las provincias a partir de 1860 experimentaron un crecimiento de sus ingresos, tendencia se aceleró en el decenio de 1880. Dentro de este panorama general la recaudación de las provincias del Litoral durante la mayor parte de la etapa fue superior en términos absolutos y relativos a la de los distritos del Interior. ${ }^{54}$ Se destaca sobre todo el espectacular crecimiento, a partir de la década de 1850, de los ingresos de la provincia de Santa Fe. En ese lapso Entre Ríos se mantuvo como la provincia de mayores ingresos después de Buenos Aires en tanto que Corrientes contaba con una base financiera más sólida que la mayoría de los otros distritos. En la década de 1880, sin embargo, los ingresos de ambas provincias tendieron a estabilizarse al tiempo que crecía aceleradamente la recaudación de Santa Fe, Córdoba, Tucumán y Mendoza. Ello reflejaba el mayor dinamismo de las provincias que se integraban al modelo agroexportador (Santa Fe y Córdoba) o desarrollaban sus producciones regionales (Tucumán y Mendoza) en relación con las economías fundadas en la ganadería tradicional.

52 Fuentes Cuadro 9: República Argntina (1873). Agote (1885 y 1888); Balán y López (1977); De los Ríos (2013); Herrera (2010). En varios casos las cifras de recaudación de las provincias del interior correspondientes a las décadas de 1860 y 1870 están expresadas en pesos bolivianos. Para la conversión a pesos moneda nacional se ha utilizado la relación $\$ 1$ boliviano $=\$ 0,76 \mathrm{~m} / \mathrm{n}$ salvo en los casos de Tucumán y Mendoza donde de acuerdo con sus oficinas de hacienda la cotización era $\$ 1 b=\$ 0,58 \mathrm{~m} / \mathrm{n}$ y $\$ 1 \mathrm{~b}=\$ 0,64$ $\mathrm{m} / \mathrm{n}$, respectivamente.

53 Según los datos de Pedro Agote hacia 1875 la recaudación consolidada de la Nación y las provincias alcanzaba a $\$ 25.709 .346$, de ese monto, el $69,1 \%$ correspondía a la Nación, el $20 \%$, a Buenos Aires y el $10,9 \%$ a las catorce provincias restantes. En 1886 el total de los ingresos fue de $\$ 53.702 .571$ de los que el $78,7 \%$ pertenecía a la Nación, el $9,8 \%$ a Buenos Aires y el $11,5 \%$ a las demás provincias.

54 Cálculo del ingreso per cápita de las provincias en 1875 y 1885. Entre Ríos: 5,5 y 5,6; Santa Fe: 3 y 4,1; Corrientes: 2,8 y 3,5; Córdoba: 1,2 y 2,5; Tucumán: 0,9 y 2,3; Salta: s/d y 2,5; Jujuy: 1 y 1,5; La Rioja: 1,2 y 1,5; Santiago del Estero: 0,4 y 1,1; Catamarca: 1,2 y 1; Mendoza: 1,4 y 2,6; San Juan 2,9 y 3,8; San Luis. 1,3 y 2,3. 
Cuadro 10. Composición de los ingresos de las provincias argentinas (\% del total)

\begin{tabular}{|c|c|c|c|c|c|c|c|c|c|}
\hline & \multicolumn{3}{|c|}{1869} & \multicolumn{3}{|c|}{1875} & \multicolumn{3}{|c|}{1885} \\
\hline & 1 & 2 & 3 & 1 & 2 & 3 & 1 & 2 & 3 \\
\hline Santa Fe & 57,2 & 7 & 38,5 & 68,5 & 4 & 31,5 & 60,8 & 0 & 40,2 \\
\hline Entre Ríos & $s / d$ & $s / d$ & $s / d$ & 68,3 & 3,1 & 28,6 & 81,9 & 2,5 & 15,6 \\
\hline Corrientes & 55,3 & 12,6 & 32,1 & 47 & 8,9 & 44,1 & 65,6 & 4,7 & 29,7 \\
\hline Córdoba & $75,5^{*}$ & $11,3^{*}$ & $13,2^{*}$ & 92,2 & 0 & 7,8 & 86,5 & 2,2 & 12,3 \\
\hline Tucumán & 63,6 & 20,8 & 15,6 & 79,8 & 17,2 & 3 & 82,6 & 1,1 & 16,3 \\
\hline S. del Estero & $52,5^{*}$ & $30,1^{*}$ & $17,4^{*}$ & 82,9 & 10,7 & 6,4 & 82,6 & 4,9 & 12,5 \\
\hline Catamarca & $57,8^{*}$ & $40,1^{*}$ & $2,1^{*}$ & 72,4 & 22,7 & 4,9 & 87 & 11,6 & 1,4 \\
\hline La Rioja & $47,4^{*}$ & $51,3^{*}$ & $1,3^{*}$ & 44,6 & 54,1 & 1,3 & 65,1 & 27,7 & 7,2 \\
\hline Jujuy & $28,7^{*}$ & $41,3^{*}$ & $30 *$ & $s / d$ & 61,8 & $s / d$ & 69,8 & 24 & 6,2 \\
\hline San Luis & $43,2^{*}$ & $44,6^{*}$ & $12,2^{*}$ & 21,7 & 54,2 & 24,1 & 62,6 & 8 & 19,4 \\
\hline Mendoza & 73,1 & 21 & 5,9 & 82,1 & 14 & 3,9 & 92,7 & 0 & 7,3 \\
\hline San Juan & $63,1^{*}$ & $21^{*}$ & $15,9 *$ & 77,5 & 17,4 & 5,1 & 84,6 & 3,7 & 11,7 \\
\hline
\end{tabular}

1: Impuestos; 2: Aportes de la Nación; 3: Otras fuentes de ingreso.

*Ingresos presupuestados

El crecimiento cuantitativo de la recaudación de las provincias también se vio acompañado por un cambio en la composición de los ingresos. En las etapas iniciales de la organización nacional cuando todavía no estaba plenamente consolidado el poder estatal, los auxilios de diversa índole provenientes de la nación constituyeron un componente importante en total de las rentas y en algunos casos, representaron la principal fuente de ingreso. Sin embargo, a medida que se afianzaba la paz interior y las provincias organizaban sus estructuras fiscales, el aporte nacional directo perdió importancia al tiempo que crecían los ingresos propios, en particular las entradas provenientes de impuestos. A mediados de la década de 1880 los recursos tributarios representaban más del 80\% del total en la mayoría de las jurisdicciones. No obstante, en el caso de Jujuy y la Rioja el aporte nacional era todavía considerable. Asimismo, Santa Fe y Corrientes tenía una alta proporción de ingresos no tributarios. En el caso de Santa Fe provenían de los dividendos obtenidos por el Banco controlado por el Estado mientras que en Corrientes corresponden sobre todo a la venta de tierras lo que pone en relieve su fuerte dependencia de este recurso

En esta etapa también creció la importancia del uso del crédito. Este instrumento permitió a las provincias con mayor capacidad de pago superar las limitaciones del presupuesto y ampliar sus gastos para el fomento de las actividades económicas y la realización de obras públicas, mientras que para las más pobres fue el medio para cubrir los faltantes en los gastos corrientes. En este aspecto Buenos Aires superaba al resto ya que desde los momentos iniciales de la etapa independiente utilizó de diversos mecanismos de endeudamiento (bonos, préstamo del exterior, emisión de moneda). Las demás provincias debieron manejarse en un marco mucho más estrecho apelando a la colocación de títulos y la postergación de los pagos. En década de 1870, sin embargo, algunas accedieron a otras fuentes de crédito por lo que su deuda creció considerablemente. Un caso excepcional es el de Santa Fe que obtuvo en 1872 un flujo extraordinario 
de fondos a través un préstamo externo que le permitió integrar el capital de un banco provincial. La entidad, que comenzó a funcionar en 1873, regularmente otorgó adelantos de fondos al gobierno. Debido a los compromisos con el exterior y con el banco para 1884 el monto de la deuda de la provincia era catorce veces superior al ingreso de ese año. Aunque en mucho menor medida también Córdoba y Entre Ríos tenían una deuda considerable que en gran parte provenía de la contratación de préstamos externos (Entre Ríos en 1871 y Córdoba en 1883). Además, Córdoba mediante un empréstito interno reunió los fondos para la creación de un banco de emisión local que también aportó recursos. Al parecer, aunque a escala mucho más modesta, un papel similar cumplió en la provincia de Mendoza el banco de Cuyo (1871). ${ }^{55}$ El resto de las provincias, entre las que se encontraba Corrientes, continuaron manejándose con instrumentos tradicionales aunque a partir de la década de 1880 también pudieron acceder a los créditos del Banco Nacional. En estas provincias el volumen del endeudamiento en relación los ingresos era mucho menor salvo en aquellas, como Santiago del Estero, con limitada capacidad de pago. ${ }^{56}$

\section{Conclusiones}

Como resultado de la instauración del régimen federal a partir de 1853 las provincias cedieron una parte considerable de sus atribuciones y recursos para crear una autoridad nacional y el régimen municipal. Estas reformas implicaron modificaciones fundamentales en la organización y funciones de los Estados provinciales. En el caso de Corrientes durante primeras décadas del siglo XIX la organización estatal había funcionado más o menos eficazmente en parte porque contaba con ingresos regulares provenientes de los impuestos aduaneros. Sin embargo, a mediados de la centuria la situación fiscal de la provincia era precaria como consecuencia de la larga lucha contra Rosas. La transferencia de las aduanas fluviales a la jurisdicción nacional acentuó la crisis dado que produjo una brusca disminución de sus ingresos tributarios. La reorganización del sistema impositivo basado en los gravámenes a la propiedad y el comercio se llevó adelante entre 1855 y 1869. En ese lapso de transición la venta de tierras fiscales y los subsidios del gobierno nacional, dos nuevas fuentes de ingreso, adquirieron importancia fundamental para compensar la pérdida de los recursos impositivos. A partir de la década de 1870 se manifestaron los resultados de las reformas de los años anteriores por lo que aumentaron en forma sostenida los ingresos regulares. En ese lapso disminuyó la importancia del aporte nacional al tesoro de la provincia aunque al mismo tiempo crecieron las inversiones la Nación en obras públicas. En términos generales, la evolución de las finanzas de Corrientes fue similar a la del resto de las provincias. En todas ellas luego de una crisis inicial se produjo un crecimiento de los ingresos propios y una menor dependencia del aporte de la

55 En 1884 el valor de la deuda cordobesa era 299\% superior a la recaudación de ese año, la de Entre Ríos, $188 \%$ y la de Mendoza, $173 \%$.

56 En 1884 proporción de la deuda sobre la recaudación era la siguiente: San Juan, 126\%; Santiago del Estero, 122\%; Corrientes, 64\%; Jujuy, 53\%; La Rioja, 24\%; Catamarca, 10\%; Tucumán ¿20\%? 
Nación para los gastos administrativos. Por el volumen de sus recursos, Corrientes se encontraba en una situación intermedia entre las provincias más ricas del Litoral y las del Interior aunque era fuertemente dependiente de la venta de tierras, un bien que tendía agotarse.

En lo que se refiere a la utilización de los recursos, el traspaso de funciones a la esfera nacional, en particular la defensa, permitió reorientar los fondos a otras necesidades de gobierno. En este lapso el gasto público se dedicó casi exclusivamente a la modernización de la estructura estatal, el fortalecimiento de la seguridad interna y el impulso de la instrucción primaria. Durante la mayor parte del período estudiado el equilibrio fiscal fue el objetivo que presidió el manejo de las finanzas. No obstante, las diversas administraciones regularmente recurrieron al endeudamiento para cubrir los déficits en los gastos corrientes y las erogaciones extraordinarias que provocaban los conflictos políticos. Las entradas de diverso origen dejaban muy poco margen para las inversiones destinadas a incrementar el capital social y promover progreso económico. En este aspecto Corrientes se diferenciaba de otras provincias (Buenos Aires, Santa Fe, Entre Ríos, Córdoba) que, mediante la obtención de préstamos en el exterior y de bancos locales, pudieron ampliar considerablemente sus gastos a cambio de un fuerte endeudamiento. Corrientes se encontraba dentro del grupo de provincias con limitado acceso al crédito pero con una relación mucho más equilibrada entre los recursos y la deuda pública. Los préstamos se obtuvieron a través de la emisión de bonos en el mercado local y a partir de 1879, de adelantos del Banco Nacional. Recién a fines de la década de 1880 se pudo acceder a un crédito en el exterior aunque el monto obtenido estaba más allá de las posibilidades de pago de la provincia. 


\section{Bibliografía}

" Agote, P. (1885). Informe del presidente del Crédito Público sobre la deuda Pública, bancos y emisiones de papel moneda y acuñación de monedas de la República Argentina, Libro III, Buenos Aires: Imp. La Universidad.

" Agote, P. (1887). Informe del presidente del Crédito Público sobre la deuda Pública, bancos y emisiones de papel moneda y acuñación de monedas de la República Argentina, Libro IV, Buenos Aires: Lit. Imp. y Enc. Guillermo Kraft.

" Agote, P. (1888). Informe del presidente del Crédito Público sobre la deuda Pública, bancos y emisiones de papel moneda y acuñación de monedas de la República Argentina, Libro V, Buenos Aires: Establecimiento de impresiones Guillermo Kraft.

" Álvarez, J. (1929). Temas de historia económica argentina. Buenos Aires: El Ateneo.

" Auza, N. T. (1971). El ejército en la época de la Confederación 1852-1861. Buenos Aires: Círculo Militar.

" Balán, J. y López, N. (1977). Burguesías y gobiernos provinciales en la Argentina: La política impositiva de Tucumán y Mendoza entre 1873 y 1914. Desarrollo Económico, 17 (67), pp. 391-435.

" Bonaudo, M. y Sonzogni, E. (1997). E1 problema de la fiscalidad en la reorganización provincial en la etapa posrosista. Santa Fe (1853-1880). Prohistoria, 1 (1).

" Botana, N. (1993). El federalismo liberal en la Argentina 1852-1930", en Carmagnani, M. (coord.) Federalismos latinoamericanos: México/Brasil/Argentina. México: Fondo de Cultura Económica, pp. 224-262.

" Buchbinder, P. (2004). Caudillos de pluma y hombres de acción. Estado y política en Corrientes en tiempos de la organización nacional. Buenos Aires: Prometeo.

"Cárcano, M. A. (1972). Evolución histórica del régimen de la tierra pública, 1810-1916, $3^{\circ}$ ed.. Buenos Aires: Eudeba.

"Chiaramonte, J. C. (1991). Mercaderes del Litoral, Economía y sociedad en la provincia de Corrientes durante la primera mitad del siglo XIX. Buenos Aires: Fondo de Cultura Económica.

"Chiaramonte, J. C. (1993). El federalismo argentino en la primera mitad del siglo XIX, en Carmagnani, M. (coord.) Federalismos latinoamericanos: México/Brasil/Argentina. México: Fondo de Cultura Económica, pp. 81-134.

" Coria, L. A. y Varo, R. (2000). Federalismo y república reales en tres décadas de presupuestos provinciales (Mendoza, 1853-1890). Anales AAEP, Córdoba.

"Cortés Conde, R. (1989). Dinero, deuda y crisis. Evolución fiscal y monetaria argentina. Buenos Aires: Sudamericana

"De los Rios, E. (2013). Hacia un nuevo orden fiscal. Las formas de recaudación impositiva: instituciones, agentes y recursos. Santa Fe, Argentina (1852-1873), Tesis Doctoral, Universitat Pompeu Fabra.

"Echeverría, C. y Contreras, R. (1873). Informe acerca de la provincia de Corrientes presentado a la Comisión directiva de la Exposición Nacional de Córdoba. Buenos Aires.

" Garavaglia, J. C. (2015). La disputa por la construcción nacional argentina. Buenos Aires, la Confederación y las provincias. Buenos Aires: Prometeo. 
" Gerchunoff, P., Rocchi, F. y Gastón Rossi 2008). Desorden y Progreso. Las crisis económicas argentinas, 1870-1905. Buenos Aires: Edhasa

" Gómez, H. (1922). Instituciones de la provincia de Corrientes. Buenos Aires: s.e..

" Herrera, C. (2010). Fiscalidad y poder: las relaciones entre el estado tucumano y el estado central en la formación del sistema político nacional, 1852-1869, en Bragoni, Beatriz y Míguez, Eduardo (Coords.) Un nuevo orden político. Provincias y Estado Nacional 18521880. Buenos Aires: Biblos, pp. 181-207.

" Herrera, C. y Parolo, M. P. (2012). Las dos caras de la fiscalidad: Estado y Contribuyentes. Tucumán, 1853-1870. Boletín del Instituto de Historia Argentina y Americana Dr. Emilio Ravignani, 34, pp. 47-76.

"J Justiniano, M. F. (2010). Entramados del poder. Salta y la nación en el siglo XIX. Bernal: Universidad de Quilmes.

" Maeder, E. (1969). Evolución demográfica Argentina desde 1810 a 1869. Buenos Aires: Eudeba.

" Oszlak, O. (2015). La formación del Estado argentino. Orden progreso y organización nacional. Buenos Aires: Ariel.

" Parolo, M. P. y Fandos, C. (2010). La modernización fiscal y sus respuestas sociales. Tucumán y Jujuy en la segunda mitad del siglo XIX, en Teruel, Ana (dir.) Problemas nacionales en escalas locales. Instituciones, actores y prácticas de la modernización en Jujuy. Rosario: Prohistoria, pp. 55-91.

" Pujol, J. (1911). Corrientes en la organización Nacional. Buenos Aires: Kraft, tomo IV.

" República Argentina (1873). Rejistro Estadístico de la República Argentina. 1869, 1870 y 1871. Buenos Aires.

" República Argentina (1883). Registro Nacional de la República Argentina, Tomo IV: 1857 a 1862. Buenos Aires: Imp. Especial de Obras "La República".

" República Argentina (1884a). Registro Nacional de la República Argentina, Tomo V: 1863 a 1869. Buenos Aires: Imp. Especial de Obras "La República”.

" República Argentina (1884b). Registro Nacional de la República Argentina, Tomo VI: 1870 a 1873. Buenos Aires: Imp. Especial de Obras "La República"

" Rex Bliss, S. (2004). La Fiscalidad provincial entre la constitución y el despegue azucarero. Tucumán, 1852-1876. América Latina en la Historia Económica, 21, pp. 119-140.

"Schaller, E. (2000). El papel moneda de la provincia de Corrientes (1841-1863). XX Encuentro de Geohistoria Regional, Resistencia, t. II.

"Schmit, R. (2008). Los límites del progreso: expansión rural en los orígenes del capitalismo rioplatense. Entre Ríos 1852-1872. Buenos Aires: Siglo XXI. 


\section{Anexo}

Cuadro I. Evolución de los ingresos y gastos de la provincia de Corrientes (1849-1889)

\begin{tabular}{|c|c|c|c|c|c|}
\hline Año & Ingresos & Gastos & Saldo & $\begin{array}{c}\text { Superávit } \\
\text { (\%) }\end{array}$ & $\begin{array}{c}\text { Déficit } \\
(\%)\end{array}$ \\
\hline 1849 & 108.414 & 95.147 & 13.267 & 12,2 & - \\
\hline 1850 & 81.563 & 77.173 & 4.390 & 5,4 & - \\
\hline 1851 & 97.297 & 90.260 & 7.037 & 7,2 & - \\
\hline 1852 & 196.488 & 163.573 & 32.915 & 16,8 & - \\
\hline 1853 & 136.651 & 143.162 & -6.511 & - & 4,8 \\
\hline 1854 & 92.394 & 114.825 & -22.431 & - & 24,3 \\
\hline 1855 & 54.850 & 67.944 & -13.094 & - & 23,9 \\
\hline 1856 & 34.226 & 79.066 & -44.840 & - & 131 \\
\hline 1857 & 78.518 & 99.811 & -21.293 & - & 48,6 \\
\hline 1858 & 78.560 & 87.629 & -9.069 & - & 11,6 \\
\hline 1859 & 141.960 & 175.280 & -33.320 & - & 23,5 \\
\hline 1860 & 178.367 & 165.115 & 1.336 & 0,7 & - \\
\hline 1861 & 127.288 & 169.880 & -42.592 & - & 33,5 \\
\hline 1862 & 176.011 & 172.105 & 3.906 & 2,2 & - \\
\hline 1863 & 155.964 & 138.253 & 17.711 & 11,4 & - \\
\hline 1864 & 204.529 & 174.396 & 30.133 & 14,7 & - \\
\hline $1865 / 1866$ & 218.779 & 233.676 & -14.897 & - & 6,8 \\
\hline 1867 & 214.529 & 225.982 & -11.453 & - & 5,3 \\
\hline 1868 & 186.551 & 350.182 & -163.631 & - & 87,7 \\
\hline 1869 & 263.472 & 275.524 & -12.052 & - & 4,6 \\
\hline 1870 & 261.382 & 302.837 & -41.455 & - & 15,6 \\
\hline 1871 & 212.637 & ¿305.000? & ¿-93.360? & - & ¿86? \\
\hline 1872 & 278.107 & 333.487 & -55.470 & - & 19,9 \\
\hline 1873 & 364.954 & ¿395.500? & $\dot{c}-30.546 ?$ & & ¿9,7? \\
\hline 1874 & 435.088 & 490.612 & -55.524 & - & 12,8 \\
\hline 1875 & 423.202 & 446.093 & -2.891 & - & 5,4 \\
\hline 1876 & 415.202 & 446.525 & -1.323 & - & 7,5 \\
\hline 1877 & 406.709 & 405.330 & 1.379 & 0,3 & - \\
\hline 1878 & 323.632 & 484.531 & -160.899 & - & 49,7 \\
\hline 1879 & 518.351 & 634.140 & -115.789 & - & 22,3 \\
\hline 1880 & 530.971 & 475.882 & 55.089 & 10,4 & - \\
\hline 1881 & 939.069 & 957.647 & -18.578 & - & 2 \\
\hline 1882 & 590.546 & 776.882 & -186.336 & - & 31,6 \\
\hline 1883 & 617.403 & 677.421 & -60.018 & - & 9,7 \\
\hline 1884 & 657.989 & 807.989 & -150.000 & - & 22,8 \\
\hline 1885 & 623.918 & 857.015 & -233.097 & - & 37,4 \\
\hline 1886 & 681.315 & 904.861 & -223.546 & - & 32,8 \\
\hline 1887 & 888.608 & 1.240 .908 & -352.300 & - & 39,6 \\
\hline 1888 & 1.021 .469 & 1.625 .839 & -604.370 & - & 59,2 \\
\hline 1889 & 992.657 & 1.672 .869 & -680.212 & - & 68,5 \\
\hline
\end{tabular}


Cuadro II. Composición de los ingresos de la provincia de Corrientes (1850-1888). En pesos.

\begin{tabular}{|c|c|c|c|c|c|c|c|c|}
\hline Año & Impuestos & $\%$ & $\begin{array}{c}\text { Adjudicación } \\
\text { de Tierras }\end{array}$ & $\%$ & Subsidios & $\%$ & Eventuales & $\%$ \\
\hline 1850 & 71.018 & 87,1 & - & - & 0 & - & 10.545 & 12,9 \\
\hline 1851 & 91.476 & 94 & - & - & 0 & - & 5.821 & 4 \\
\hline 1852 & 106.148 & 58,5 & - & - & 53.093 & 29,3 & 19.356 & 12,2 \\
\hline 1853 & 63.310 & 69,9 & - & - & 11.456 & 12,7 & 15.795 & 17,4 \\
\hline 1854 & 62.540 & 82,2 & - & - & 9.950 & 13 & 3.639 & 4,8 \\
\hline 1855 & 36.916 & 71,5 & - & - & 14.725 & 28,5 & & \\
\hline 1856 & 13.564 & 42 & 6.080 & 18,8 & 0 & - & 12.631 & 39,2 \\
\hline 1857 & 42.009 & 58,4 & 16.031 & 22,3 & 0 & - & 13.816 & 19,3 \\
\hline 1858 & 41.978 & 55,9 & 23.809 & 31,7 & 1.110 & 1,5 & 8.204 & 10,9 \\
\hline 1859 & 40.135 & 28,8 & 96.687 & 69,3 & 1.000 & 0,7 & 1.752 & 1,2 \\
\hline 1860 & 44.013 & 28,8 & 106.697 & 69,8 & 0 & - & 2.031 & 1,4 \\
\hline 1861 & 42.456 & 34,8 & 70.491 & 57,4 & 0 & - & 9.921 & 7,8 \\
\hline 1862 & 47.211 & 26,8 & 42.304 & 24 & 81.803 & 46,5 & 4.693 & 2,5 \\
\hline 1863 & 69.299 & 61,6 & 33.913 & 30,1 & 8.818 & 7,8 & 507 & 0,5 \\
\hline 1864 & 93.661 & 45,7 & 84.978 & 41,5 & 26.250 & 12,8 & $?$ & $?$ \\
\hline $1865 / 1866$ & 91.233 & 42,8 & 33.226 & 15,6 & 79.368 & 37,2 & 9.406 & 4,4 \\
\hline 1867 & 113.331 & 52,8 & 54.190 & 25,3 & 37.156 & 17,3 & 9.852 & 4,6 \\
\hline 1868 & 89.545 & 48 & 60.906 & 32,6 & 33.534 & 18 & 2.563 & 1,4 \\
\hline 1869 & 145.591 & 55,3 & 79.354 & 30,1 & 33.268 & 12,6 & 5.257 & 2 \\
\hline 1870 & 137.105 & 55 & 93.129 & 37,4 & 17.000 & 6,8 & 2.093 & 0,8 \\
\hline 1871 & 135.711 & 63,8 & 59.893 & 22,9 & 17.000 & 13,3 & 33 & - \\
\hline 1872 & 166.756 & 60 & 88.486 & 31,8 & 20.000 & 7,2 & 2.775 & 1 \\
\hline 1873 & 172.916 & 47,4 & 161.928 & 44,4 & 21.222 & 5,8 & 8.888 & 2,4 \\
\hline 1874 & 180.692 & 38,5 & 191.491 & 40,9 & 46.958 & 19,6 & 4.361 & 1 \\
\hline 1875 & 199.142 & 47 & 180.014 & 42,5 & 37.876 & 8,9 & 5.470 & 1,6 \\
\hline 1876 & 250.660 & 60,4 & 123.330 & 29,7 & 34.199 & 8,2 & 6.985 & 1,7 \\
\hline 1877 & 221.954 & 54,6 & 149.663 & 36,8 & 25.280 & 6,2 & 9.812 & 2,4 \\
\hline 1878 & 168.259 & 51,8 & 133.628 & 41,3 & $16.40 \mathrm{I}$ & 5,1 & 5.305 & 1,8 \\
\hline 1879 & 254.381 & 49,1 & 228.099 & 44 & 25.359 & 4,9 & 10.502 & 2 \\
\hline 1880 & 317.933 & 58 & 196.288 & 37 & 2.286 & 0,4 & 14.464 & 4,6 \\
\hline 1881 & 308.378 & 32,8 & 617.832 & 65,6 & 0 & - & 12.859 & 1,6 \\
\hline 1882 & 341.665 & 57,9 & 239.435 & 40,5 & 0 & - & 9.446 & 1,6 \\
\hline 1883 & 374.594 & 60,7 & 189.993 & 30,8 & 30.903 & 5 & 21.913 & 3,5 \\
\hline 1885 & 409.589 & 65,6 & 176.843 & 28,3 & 29.545 & 4,7 & 7.997 & 1,4 \\
\hline 1886 & 461.016 & 67,7 & 181.419 & 26,6 & 33.382 & 4,9 & 5.493 & 0,8 \\
\hline 1887 & 473.806 & 53,3 & 378.996 & 42,6 & 22.497 & 2,5 & 13.319 & 1,6 \\
\hline 1888 & 585.278 & 57 & 420.916 & 41,2 & $?$ & $?$ & 15.274 & 1,8 \\
\hline
\end{tabular}

Cuadro III. Ingresos impositivos de la provincia de Corrientes (1850-1889). En pesos

\begin{tabular}{|c|c|c|c|c|c|c|c|c|}
\hline Año & Aduanas & $\begin{array}{c}\text { Contribución } \\
\text { Directa }\end{array}$ & Patentes & $\begin{array}{c}\text { Guías } \\
\text { Hacienda }\end{array}$ & $\begin{array}{l}\text { Guías } \\
\text { Frutos }\end{array}$ & Policiales & Sellados & Otros \\
\hline 1850 & 58.208 & - & 8.265 & - & - & 347 & 4.198 & - \\
\hline 1851 & 85.302 & - & 3.588 & - & - & 192 & 2.394 & - \\
\hline 1852 & 104.077 & - & 4.388 & - & - & 68 & 3.147 & 715 \\
\hline 1853 & 53.284 & - & 6.208 & - & - & 63 & 2.962 & 793 \\
\hline 1854 & 48.347 & - & 6.858 & - & - & 4.440 & 2.805 & - \\
\hline 1855 & 26.562 & - & 6.989 & - & - & - & 3.277 & 88 \\
\hline 1856 & - & - & 11.164 & - & - & - & 1.706 & 694 \\
\hline
\end{tabular}




\begin{tabular}{|c|c|c|c|c|c|c|c|c|}
\hline 1857 & - & 12.577 & 8.244 & - & - & 18.389 & 2.250 & 549 \\
\hline 1858 & & 13.229 & 8.515 & - & - & 16.475 & 1.238 & 2.521 \\
\hline 1859 & - & 16.302 & 12.736 & - & - & 5.910 & 3.199 & 1.988 \\
\hline 1860 & & 23.341 & 10.744 & - & - & 6.171 & 2.169 & 1.418 \\
\hline 1861 & - & 30.257 & 7.453 & - & - & $s / d$ & 2.719 & 2.027 \\
\hline 1862 & - & 27.571 & 12.997 & - & - & 1.831 & 3.255 & 1.557 \\
\hline 1863 & - & 23.978 & 16.087 & - & - & 20.870 & 5.085 & 3.279 \\
\hline 1864 & - & 32.000 & 25.071 & - & - & 13.302 & 9.840 & 13.448 \\
\hline $1865 / 66$ & - & 29.832 & 32.148 & - & - & 13.663 & 7.547 & 8.043 \\
\hline 1867 & - & 54.000 & 35.903 & - & - & 8.797 & 9.301 & 5.330 \\
\hline 1868 & - & 16.032 & 34.257 & 7.033 & - & 20.953 & 6.643 & 4.627 \\
\hline 1869 & - & 47.069 & 42.680 & 21.832 & - & 11.102 & 11.953 & 10.955 \\
\hline 1870 & - & 39.767 & 42.426 & 14.179 & - & 10.650 & 12.368 & 17.715 \\
\hline 1871 & - & 40.384 & 39.462 & 22.942 & - & 13.240 & 11.260 & 8.423 \\
\hline 1872 & - & 55.390 & 49.208 & 26.005 & - & 10.716 & 15.180 & 9.455 \\
\hline 1873 & - & 49.384 & 61.479 & 24.276 & - & 8.170 & 15.755 & 13.851 \\
\hline 1874 & - & 56.280 & 62.049 & 25.470 & - & 5.192 & 15.638 & 16.142 \\
\hline 1875 & - & 58.698 & 66.999 & 28.238 & - & 1.887 & 18.545 & 25.475 \\
\hline 1876 & - & 50.444 & 94.913 & 58.905 & - & 2.021 & 18.641 & 25.736 \\
\hline 1877 & - & 48.580 & 67.963 & 69.842 & - & 2.326 & 15.156 & 18.087 \\
\hline 1878 & - & 43.108 & 52.845 & 51.815 & - & 1.994 & 8.972 & 9.525 \\
\hline 1879 & - & 47.033 & 62.487 & 80.937 & - & 26.001 & 21.856 & 16.067 \\
\hline 1880 & - & 63.135 & 89.582 & 80.434 & 16.323 & 34.258 & 17.914 & 16.287 \\
\hline 1881 & - & 63.567 & 89.909 & 73.738 & 11.961 & 31.685 & 24.177 & 13.341 \\
\hline 1882 & - & 91.192 & 99.766 & 81.182 & 13.894 & 28.679 & 23.383 & 3.570 \\
\hline 1883 & - & 78.340 & 105.560 & 100.048 & 16.593 & 35.725 & 30.952 & 18.511 \\
\hline 1885 & - & 122.242 & 96.947 & 90.738 & 20.710 & 40.483 & 26.043 & 12.075 \\
\hline 1886 & - & 139.308 & 99.292 & 108.888 & 20.936 & 38.086 & 30.431 & 24.075 \\
\hline 1887 & - & 155.222 & 109.046 & 103.581 & 21.141 & 40.072 & 38.792 & 5.942 \\
\hline 1888 & - & 220.497 & 128.917 & 119.184 & 22.774 & 41.900 & 46.293 & $s / d$ \\
\hline 1889 & - & 149.097 & $s / d$ & $s / d$ & $s / d$ & $s / d$ & $s / d$ & $s / d$ \\
\hline
\end{tabular}

\section{Cuadro IV. Distribución porcentual del gasto público entre 1850 y 1887}

\begin{tabular}{|c|c|c|c|c|c|}
\hline Año & $\begin{array}{c}\text { Gobierno y } \\
\text { Hacienda }\end{array}$ & $\begin{array}{l}\text { Seguridad y } \\
\text { Defensa }\end{array}$ & Educación & $\begin{array}{c}\text { Obras } \\
\text { públicas }\end{array}$ & $\begin{array}{l}\text { Servicio de } \\
\text { la deuda }\end{array}$ \\
\hline
\end{tabular}

\begin{tabular}{ccccccc}
\hline 1850 & 17 & 74 & - & 2,6 & 6,4 & - \\
\hline 1851 & 34,8 & 63,6 & - & - & 1,6 & - \\
\hline 1852 & 32,5 & 44,6 & - & 6,3 & 10,4 & 6,2 \\
\hline 1853 & 32,5 & 60,9 & - & 6,6 & - & - \\
\hline 1854 & 66,2 & 31,9 & - & 1,9 & - & - \\
\hline 1855 & 65 & 7,3 & 10,3 & 5,2 & 2,8 & 9,4 \\
\hline 1856 & 36,6 & 9,4 & 14,4 & 27,1 & 10,2 & 2,3 \\
\hline 1857 & 52,9 & 23,2 & 13,5 & 1 & 8,9 & 0,5 \\
\hline 1858 & 51,1 & 30 & 15,1 & 0 & 2,6 & 1,2 \\
\hline 1859 & 46,1 & 29,3 & 12,1 & 12,5 & - & - \\
\hline 1860 & 30,2 & 21,8 & 7,3 & 20 & 14 & 6,4 \\
\hline 1861 & 34,3 & 24,7 & 7 & 14,3 & 11,9 & 7,8 \\
\hline
\end{tabular}




\begin{tabular}{ccccccc}
\hline 1862 & 20,7 & 50,4 & 4,4 & 2,6 & 16 & 5,9 \\
\hline 1863 & 36,4 & 29,4 & 14,7 & 3,5 & 16,1 & 0 \\
\hline 1864 & 29 & 30,6 & 4,1 & 4,2 & 32,1 & 0 \\
\hline $1865 / 1866$ & 22,9 & 44,3 & 1,9 & 2,8 & 18,1 & 10 \\
\hline 1868 & 20,4 & 69,2 & 0,7 & 1,9 & 6,8 & 1 \\
\hline 1870 & 23,6 & 50,3 & 7,7 & 1 & 13,7 & 3,7 \\
\hline $1873 *$ & 23,3 & 43,8 & 5,2 & 2,2 & 25 & 0,5 \\
\hline 1874 & 25,5 & 40,2 & 8,6 & 1,5 & 23 & 1,2 \\
\hline 1875 & 22 & 42,1 & 9,3 & 2,1 & 24 & 0,5 \\
\hline 1876 & 28,7 & 40,8 & 10,4 & 2,8 & 10,9 & 6,4 \\
\hline 1877 & 33,1 & 37,9 & 7,6 & 1 & 13,3 & 7,1 \\
\hline $1878 *$ & 24 & 58,8 & 5,6 & 0,4 & 9,2 & 2 \\
\hline 1879 & 22,1 & 47,3 & 11,3 & 0,8 & 17,6 & 0,9 \\
\hline 1880 & 25,2 & 45,4 & 12,3 & 0,7 & 15,2 & 1,1 \\
\hline $1881^{*}$ & 21 & 31 & 10,6 & 1,1 & 35,7 & 0,6 \\
\hline 1882 & 21 & 35,2 & 9,3 & 0,6 & 25,7 & 8,2 \\
\hline 1883 & 23,9 & 43,1 & 14,8 & 0,7 & 12,9 & 4,6 \\
\hline 1885 & 19,3 & 37,1 & 10,3 & 2,7 & 28,4 & 2,2 \\
\hline $1886 *$ & 19,2 & 35,2 & 9,8 & 7,1 & 23,8 & 4,9 \\
\hline 1887 & 23,7 & 27,9 & 9,6 & 6,3 & 29,2 & 3,3 \\
\hline P & 21 & & & &
\end{tabular}

*Porcentaje basado en cifras parciales. 